\title{
UK Renal Registry 13th Annual Report (December 2010): Chapter 6 Survival and Causes of Death of UK Adult Patients on Renal Replacement Therapy in 2009: National and Centre-Specific Analyses
}

\author{
Clare Castledine $^{a}$, Retha Steenkamp ${ }^{a}$, Terry Feest ${ }^{a}$, Charles R V Tomson ${ }^{b}$

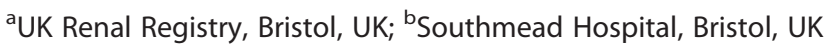

\section{Key Words}

Cause of death - Comorbidity - Dialysis - End stage renal disease - Established renal failure - Haemodialysis (HD) . Outcome - Peritoneal dialysis (PD) - Renal replacement therapy (RRT) · Survival · Transplant · Vintage

\begin{abstract}
Introduction: These analyses examine (a) survival from the start of renal replacement therapy (RRT), based on the total incident UK RRT population reported to the UK Renal Registry, including the $18 \%$ who started on PD and the $6 \%$ who received a pre-emptive transplant and (b) survival of prevalent patients. Changes in survival between 1997 and 2008 are also reported. Methods: Survival was calculated for both incident and prevalent patients on RRT and compared between the UK countries after adjustment for age. Survival of incident patients (starting RRT during 2008) was calculated both from the start of RRT and amongst the cohort who survived at least 90 days after RRT, both with and without censoring at transplantation. Both Kaplan-Meier and Cox adjusted models were used to calculate survival. Causes of death were analysed for both groups. Relative risk of death was calculated
\end{abstract}

compared with the general UK population. Results: The 2008 unadjusted 1 year after 90 day survival for patients starting RRT was $87.3 \%$. In incident patients aged 18-64, the unadjusted 1 year survival had risen from $85.9 \%$ in 1997 to $91.9 \%$ in 2008 and for those aged $\geqslant 65$ it had risen from $64.2 \%$ to $75.8 \%$. The age-adjusted one year survival (adjusted to age 60) of prevalent dialysis patients rose from $85 \%$ in 2000 to $89 \%$ in 2009 . Diabetic prevalent patient one year survival rose from $76.6 \%$ in 2000 to $83.6 \%$ in 2009 . The age-standardised mortality ratio for prevalent RRT patients compared with the general population was 19 at age 30 years and 2.4 at age 85 years. In the prevalent RRT dialysis population, cardiovascular disease accounted for $24 \%$ of deaths, infection $19 \%$ and treatment withdrawal $14 \%$; $22 \%$ were recorded as uncertain. Treatment withdrawal was a more frequent cause of death in patients aged $\geqslant 65$ at start of RRT than in younger patients. The median life years remaining for a 25-29 year old on RRT was 20 years and 4 years for a $75+$ year old. Conclusions: Survival of patients starting RRT, has improved in the 2008 incident cohort. The relative risk of death on RRT compared with the general population has fallen since 2001. Death rates on dialysis in the UK remained lower than when compared with a similar aged population on dialysis in the USA.
Clare Castledine

UK Renal Registry, Southmead Hospital, Southmead Road, Bristol, BS10 5NB, UK

Email: clare@renalreg.com 


\section{Introduction}

The analyses presented in this chapter examine (a) survival from the start of renal replacement therapy (RRT); (b) the survival amongst all prevalent RRT patients alive on 1st January 2009 and (c) projected life years remaining for RRT patients. They encompass the outcomes from the total incident UK dialysis population reported to the UK Renal Registry (UKRR), including the $18 \%$ who started on peritoneal dialysis and the $6 \%$ who received a pre-emptive renal transplant. These results are therefore a true reflection of the outcomes in the whole UK RRT population and are not distorted by focusing solely on the haemodialysis cohort. Additionally, analyses of the 1st year UK survival data include patients who were recorded as having started RRT for established renal failure (as opposed to acute kidney injury) but who had died within the first 90 days of starting RRT, a group excluded from most other countries' registry data.

The term established renal failure (ERF) used throughout this chapter is synonymous with the terms end stage renal failure (ESRF) and end stage renal disease (ESRD) which are in more widespread international usage. Within the UK, patient groups have disliked the term 'end stage'; the term ERF was endorsed by the English National Service Framework for Renal Services, published in 2004.

The prevalent patient group was defined as all patients over 18 years old who had been on RRT for at least 90 days at one of the UK adult renal centres and who were alive on 31st December 2009. This included incident patients in 2009 and patients who had been on treatment for longer but excluded patients who had stopped treatment before this date.

Since 2006, the UK has openly reported and published centre-attributable RRT survival and remains the only country doing so. It is again stressed that these are raw data which continue to require very cautious interpretation. The Registry can adjust for the effects of the different age distributions of patients in different centres and the proportion of patients with diabetes, but lacks sufficient data from many participating centres to enable adjustment for other comorbidities and ethnic origin, which have been shown to have an impact on outcome (for instance, better survival is expected in centres with a higher proportion of Black and South Asian patients). This lack of information on case mix makes interpretation of any apparent difference in survival between centres difficult, although age and comorbidity, especially diabetes, are the major factors associated with survival $[1,2]$. Despite the uncertainty about any apparent differences in outcome for centres which appear to be outliers, the UKRR will follow the clinical governance procedures as set out in chapter 2 of the 2009 UKRR report [3].

\section{Methods}

The unadjusted survival probabilities (with 95\% confidence intervals) were calculated using the Kaplan-Meier method, in which the probability of surviving more than a given time can be estimated for members of a cohort of patients, without any adjustment for age or other factors that affect the chances of survival in the cohort. Where centres are small, or the survival probabilities are greater than $90 \%$, the confidence intervals are only approximate.

In order to estimate the difference in survival of different subgroups of patients within the cohort, a stratified proportional hazards model (Cox) was used where appropriate. The results from the Cox model were interpreted using a hazard ratio. When comparing two groups, the hazard ratio is the ratio of the estimated hazards for group A relative to group B, where the hazard is the risk of dying at time $t$ given that the individual has survived until this time. The underlying assumption of a proportional hazards model is that this ratio remains constant throughout the period under consideration. Whenever used, the proportional hazards model was tested for validity.

To allow comparisons between centres with differing age distributions, survival analyses were statistically adjusted for age and reported as survival adjusted to age 60 . This gives an estimate of what the survival would have been if all patients in that centre had been aged 60 at the start of RRT. This age was chosen because it was approximately the average age of patients starting RRT 14 years ago at the start of the Registry's data collection. For the last 7 years the average age of patients commencing RRT in the UK has been stable around an age of 65 years, but the Registry has maintained age adjustment to 60 years for comparability with all previous years' analyses. All analyses were undertaken using SAS vs. 9.2.

\section{Definition of the date renal replacement therapy started}

The incident survival figures quoted in this chapter are from the first day of renal replacement therapy whether with dialysis or a pre-emptive transplant.

In the UKRR all patients starting RRT for ERF are included from the date of the first RRT treatment wherever it took place (a date currently defined by the clinician) if the clinician considered the renal failure irreversible; should a patient recover renal function within 90 days they were then excluded. These UK data therefore include some patients who developed acute irreversible renal failure in the context of an acute illness for instance and were recorded by the clinician as being in irreversible established renal failure. Capture of data on these patients requires accurate coding. Previously, the Registry asked clinicians to re-enter a 
code for established renal failure in patients initially coded as having acute renal failure, once it had become clear that there was no recovery of kidney function. However, adherence to this requirement was very variable, with some clinicians entering a code for established renal failure only once a decision had been made to plan for long-term RRT [4]. All UK nephrologists have now been asked to record the date of the first haemodialysis session and to record whether the patient was considered to have acute kidney injury (acute renal failure) or to be in ERF at the time of the first session. For patients initially categorised as 'acute', but who were subsequently categorised as ERF, the UKRR will extract information from the first session of RRT onwards if available and will assign the date of this first session as the date of start of RRT.

Recent UKRR analyses of electronic data extracted for the immediate month prior to the start date of RRT provided by clinicians highlighted additional inconsistencies in the definition of this first date when patients started on peritoneal dialysis, with the date of start reported to the Registry being later than the actual date of start. These findings are described in detail in chapter 13 of the 2009 Report [4]. This concern is unlikely to be unique to the UK, but will be common to analyses from all renal centres and registries.

In addition to this varying clinical definition of day 0 , there is international variability on when patient data are collected by national registries with some countries (often for financial reimbursement or administrative reasons) defining the 90th day after starting RRT as day 0 or others collecting data only on those who have survived 90 days and reporting as zero the number of patients dying within the first 90 days. Some other countries do not include initial urgent/emergency dialysis in intensive care units or acute wards.

Thus as many other national registries do not include reports on patients who do not survive the first 90 days, survival from 90 days onwards is also reported to allow international comparisons. This distinction is important, as there is a much higher death rate in the first 90 days, which would distort any such comparisons.

\section{Methodology for incident patient survival}

Patients are considered 'incident' at the time of their first RRT, thus patients re-starting dialysis after a failed transplant were not included.

The incident survival cohort was NOT censored at the time of transplantation and therefore included the $6 \%$ who received a pre-emptive transplant. Censoring would exclude this healthier patient cohort. An additional reason for not censoring was to facilitate comparison between centres. Centres with a high proportion of patients of South Asian and Black origin are likely to have a healthier dialysis population, because South Asian and Black patients are less likely to undergo early transplantation.

The incident ('take-on') population in any specific year excludes those who recovered within 90 days from the start of RRT, but includes patients who recovered from ERF after 90 days. Patients newly transferred into a centre who were already on RRT were excluded from the incident population for that centre and were counted at the centre at which they started RRT.

Some patients recover renal function after more than 90 days but subsequently returned to RRT. If recovery was for less than 90 days, the start of renal replacement therapy was calculated from the date of the first episode and the recovery period ignored.
If recovery was for 90 days or more the length of time on RRT was calculated from the day on which the patient restarted RRT.

The one year incident survival is for patients who started RRT in 2008 and was calculated for 1 full year through 2008 and 2009 (e.g. patients starting RRT on 1st December 2008 were followed through to 30th November 2009). The 2009 incident patients could not be analysed as they had not been followed for a sufficient length of time.

For analysis of 1 year after 90 day survival, patients who started RRT in October through December 2008 were not included in the cohort, as 1st quarter 2010 data on these patients were not yet available.

To help identify any centre differences in survival from the small centres (where confidence intervals are large), an analysis of 1 year after 90 day survival using a rolling 4 year combined incident cohort from 2005 to 2008 was also undertaken. For those centres which had joined the UKRR in the previous 1-3 years, the available data were included.

The death rate per 1,000 patient years was calculated by counting the number of deaths and dividing by the person years exposed. This included all patients, including those who died within the first 3 months of therapy. The person years at risk were calculated by adding up, for each patient, the number of days at risk (until they died or were lost to follow-up) and dividing by 365 .

Adjustment of 1 year after 90 day survival for the effect of comorbidity was undertaken using a rolling 5 year combined incident cohort from 2004 to 2008. Eleven centres had returned $>85 \%$ of comorbidity data for patients in the combined cohort. Adjustment was first performed to a mean age of 60 years, then to the average distribution of primary diagnosis for all the eleven centres. The individual centre data were then further adjusted for average distribution of comorbidity present at these centres.

The survival hazard function was calculated as the probability of dying in a short time interval considering survival to that interval.

\section{Methodology for prevalent patient survival}

For dialysis patients, all who had been established on RRT for at least 90 days on 1st January 2009 were included in these analyses.

For calculating the survival of transplant patients, those who had been established with a transplant for at least 6 months were included.

As discussed in previous reports, comparison of survival of prevalent dialysis patients between centres is complex. Survival of prevalent dialysis patients can be studied with or without censoring at transplantation. When a patient is censored at transplantation, the patient is considered as alive up to the point of transplantation, but the patient's status post-transplant is not considered. This censoring could cause apparent differences in survival between those renal centres with a high transplant rate and those with a low transplant rate, especially in younger patients where the transplant rate is highest. Censoring at transplantation systematically removes younger fitter patients from the survival data. The differences are likely to be small due to the relatively small proportion of patients being transplanted in a given year compared to the whole dialysis population (about 14\% of the dialysis population aged under 65 and $1 \%$ of the population aged 65 years and over). Only the censored for transplantation results have been quoted throughout the prevalent analyses. 
Methodology of causes of death

The ERA-EDTA registry codes for causes of death were used. These have been grouped into the following categories:

- Cardiac disease

- Cerebrovascular disease

- Infection

- Malignancy

- Treatment withdrawal

- Other

- Uncertain

Some centres had high completeness of data returns to the UKRR regarding cause of death, whilst others returned no information.

Adult patients aged 18 years and over, from England, Wales, Scotland and Northern Ireland, were included in the analyses of cause of death. The incident patient analysis included all patients starting RRT in the years 2000-2008. Previously data analysis was limited to centres with a high rate of return for cause of death. When this was compared with an analysis of all the cause of death data on the database, the percentages in corresponding ERA-EDTA categories remained unchanged so the latter data were therefore included.

Analysis of prevalent patients included all those aged over 18 years and receiving RRT on 1 January 2009. The death rate was calculated for the UK general population (data from the Office of National Statistics) [5] by age band and compared with the same age band for prevalent patients on RRT on 1st January 2009.

Methodology of median life expectancy (life table calculations)

Kaplan Meier survival analyses were used to calculate the hazard of death by age group (18-34, 35-44, 45-54, 55-64, 6574, 75+) for incident patients starting RRT from 1997 to 2008. The patient cohort inclusion criteria are the same to that of the incident cohort described above. Patients were then followed until death, censoring or end of the study period.

This analysis showed that the hazard of death stabilized after year one with variability increasing again after nine years. Due to this, the average hazard of death for the periods 1 to 9 years was calculated for each age group. Life expectancy was calculated as ( 1 - hazard of death) which gives the probability of surviving until the next time period. Median life years remaining is then the difference between the age when reaching the $50 \%$ probability of survival and the age of starting RRT.

\section{Methodology for comparing mortality in prevalent RRT}

patients with the mortality in the general population

Data on the UK population in mid-2008 and the number of deaths in 2008 were obtained from the Office of National Statistics for each nation separately and added together [5]. The age-specific UK death rate was calculated as the number of UK deaths/UK population. The age-specific 'expected' rate of deaths in the RRT population was then calculated: years exposed for RRT patients $\times$ UK death rate/1,000. The age-specific observed number of RRT deaths was calculated as the actual number of deaths observed in 2009 and the RRT death rate as the actual number of deaths in 2009/years exposed for RRT patients $\times 1,000$. The observed/expected ratio was then calculated.

\section{Results of incident (new RRT) patient survival}

The 2008 cohort included 6,767 patients who started RRT, without any periods of renal function recovery lasting more than 90 days.

It is hard to set survival standards at present because these should be age, gender and comorbidity adjusted and this is not yet possible from UKRR data. The current 5th Edition of the Clinical Practice Guidelines [6] does not set any standards for audit of patient survival.

The 3rd Renal Standards document defined standard primary renal disease using the ERA-EDTA diagnosis codes (including only codes $0-49$ ); this excluded patients with renal disease due to diabetes and other systemic diseases. It is more widespread practice to simply exclude patients with diabetes, so these analyses are also included in this report to allow comparison with reports from other registries. The results are shown in table 6.1.

Table 6.1. One-year incident dialysis patient survival (from day 0-365), patients aged 18-54, 2008 and 2002 cohort (excludes patients whose first modality was transplantation)

\begin{tabular}{|c|c|c|c|c|}
\hline \multirow[b]{2}{*}{ First treatment } & \multicolumn{2}{|c|}{2008 cohort } & \multicolumn{2}{|c|}{2002 cohort } \\
\hline & $\begin{array}{l}\text { Standard primary } \\
\text { renal disease }\end{array}$ & $\begin{array}{c}\text { All primary renal diseases } \\
\text { except diabetes }\end{array}$ & $\begin{array}{l}\text { Standard primary } \\
\text { renal disease }\end{array}$ & $\begin{array}{c}\text { All primary renal diseases } \\
\text { except diabetes }\end{array}$ \\
\hline All dialysis \% & 97.6 & 96.2 & 95.4 & 93.9 \\
\hline $95 \% C I$ & $96.4-98.4$ & $95.1-97.1$ & $93.7-97.1$ & $92.2-95.5$ \\
\hline HD \% & 97.0 & 95.2 & 93.4 & 91.6 \\
\hline $95 \% C I$ & $96.9-99.7$ & $97.1-99.5$ & $71.1-100$ & $96.3-99.6$ \\
\hline
\end{tabular}


Table 6.2. Incident patient survival across the UK countries, combined 2 year cohort (2007-2008), adjusted to age 60

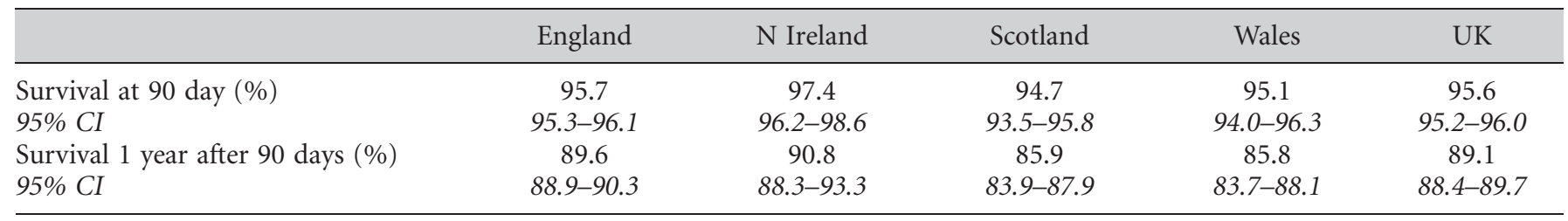

The trend of improving patient survival continued with improvement seen in both those patients with 'standard primary renal disease' and those with all other primary renal diseases (excluding diabetes). For a longer term comparison, the 2002 cohort is also shown.

\section{Comparison of survival between UK countries}

Two years' incident data have been combined to increase the size of the patient cohort, so that any differences between the 4 UK countries are more likely to be reliably identified (table 6.2). These data have not been adjusted for differences in primary renal diagnosis, ethnicity, socio-economic status or comorbidity, nor for differences in life expectancy in the general populations of the four countries. There was a significant difference in 90 day survival between the UK countries $(p=0.03)$ and the 1 year after 90 day survival was once again significantly different $(p<0.0002)$ between countries. It is postulated that greater prevalence of cardiovascular disease in Wales and Scotland compared with England may account for these differences.

\section{Modality}

It is impossible to obtain truly valid comparisons of survival of patients starting on different modalities, as modality selection is not random. In the UK patients
Table 6.3. One-year after day 90 incident patient survival by first established treatment modality (adjusted to age 60) (excluding patients whose first modality was transplantation)

\begin{tabular}{lcc} 
& \multicolumn{2}{c}{ Age adjusted 1 year after 90 days \% survival } \\
& \multicolumn{2}{c}{$95 \%$ CI } \\
\cline { 2 - 3 } Year & HD & PD \\
\hline 2008 & 88.1 & 93.8 \\
& $87.0-89.1$ & $92.5-95.2$ \\
2007 & 87.0 & 94.0 \\
& $85.9-88.1$ & $92.8-95.3$ \\
2006 & 86.8 & 94.2 \\
& $85.7-88.0$ & $92.9-95.5$ \\
2005 & 85.8 & 93.2 \\
& $84.6-87.0$ & $91.8-94.6$ \\
2004 & 85.7 & 90.4 \\
& $84.5-87.0$ & $88.8-92.1$ \\
2003 & 85.7 & 92.2 \\
& $84.3-87.1$ & $90.7-93.8$ \\
2002 & 84.0 & 90.4 \\
& $82.5-85.6$ & $88.6-92.3$ \\
\hline
\end{tabular}

starting peritoneal dialysis as a group were younger and fitter than those starting haemodialysis, and were transplanted more quickly. The age-adjusted one year survival estimates on $\mathrm{HD}$ and PD were $88.1 \%$ and $93.8 \%$ respectively which both show a trend in improvement in survival from 2002 (figure 6.1 and table 6.3).

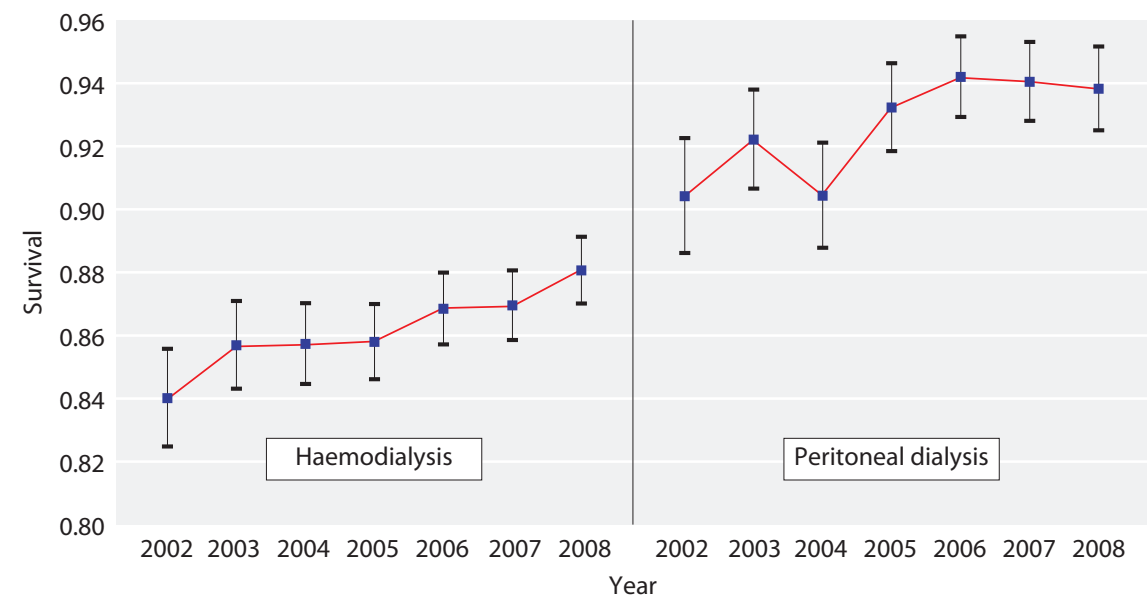

Fig. 6.1. Trend in 1 year after 90 day mortality by first established modality 2002-2008 (adjusted to age 60) (excluding patients whose first modality was transplantation) 
Table 6.4. Unadjusted 90 day survival of incident patients, 2008 cohort, by age

\begin{tabular}{lccc}
\hline Age & $\mathrm{KM}^{\star}$ survival $(\%)$ & $\mathrm{KM} 95 \% \mathrm{CI}$ & $\mathrm{N}$ \\
\hline $18-64$ & 97.3 & $96.7-97.8$ & 3,519 \\
$\geqslant 65$ & 90.1 & $89.0-91.1$ & 3,248 \\
All ages & 93.8 & $93.2-94.4$ & 6,767 \\
\hline
\end{tabular}

${ }^{*} \mathrm{KM}=$ Kaplan-Meier

Results from the USRDS and Australasian (ANZDATA) registries, after adjustment for comorbidity, are similar.

\section{Age}

Tables 6.4 to 6.9 show survival of all patients and those aged 65 and above and those aged below 65 years, for up to twelve years after initiation of renal replacement therapy. In the UK, short term survival remained similar
Table 6.5. Unadjusted 1 year after day 90 survival of incident patients, 2008 cohort, by age

\begin{tabular}{lccc}
\hline Age & KM survival (\%) & KM 95\% CI & N \\
\hline $18-64$ & 93.2 & $92.3-94.0$ & 3,400 \\
$\geqslant 65$ & 80.4 & $78.8-81.8$ & 2,921 \\
All ages & 87.3 & $86.4-88.1$ & 6,321 \\
\hline
\end{tabular}

${ }^{\star} \mathrm{KM}=$ Kaplan-Meier

Table 6.6. Increase in proportional hazard of death for each 10 year increase in age, at 90 days and for 1 year thereafter, 2008 cohort

\begin{tabular}{lcc}
\hline & $\begin{array}{c}\text { Hazard of death for } \\
\text { 10 year age increase }\end{array}$ & $95 \%$ CI \\
\hline First 90 days & 1.78 & $1.64-1.93$ \\
1 year after first 90 days & 1.58 & $1.49-1.67$ \\
\hline
\end{tabular}

Table 6.7. Unadjusted KM survival of incident patients, 1997-2008 cohort for patients aged 18-64

\begin{tabular}{|c|c|c|c|c|c|c|c|c|c|c|c|c|c|c|}
\hline Cohort & 1 year & 2 year & 3 year & 4 year & 5 year & 6 year & 7 year & 8 year & 9 year & 10 year & 11 year & 12 year & $\begin{array}{l}95 \% \text { CI for } \\
\text { latest year }\end{array}$ & $\mathrm{N}$ \\
\hline 2008 & 91.9 & & & & & & & & & & & & $90.9-92.8$ & 3,519 \\
\hline 2006 & 91.4 & 85.7 & 80.9 & & & & & & & & & & $79.5-82.3$ & 3,211 \\
\hline 2005 & 89.8 & 83.9 & 79.3 & 75.0 & & & & & & & & & $73.4-76.5$ & 3,036 \\
\hline 2004 & 89.9 & 84.1 & 78.0 & 72.5 & 67.9 & & & & & & & & $66.1-69.7$ & 2,700 \\
\hline 2001 & 87.5 & 79.9 & 74.3 & 68.8 & 64.1 & 59.7 & 56.4 & 53.2 & & & & & $50.8-55.4$ & 1,878 \\
\hline 2000 & 89.6 & 82.0 & 75.4 & 70.6 & 65.4 & 60.5 & 56.5 & 53.4 & 51.1 & & & & $48.6-53.6$ & 1,613 \\
\hline 1999 & 87.7 & 81.7 & 74.4 & 68.5 & 63.7 & 59.6 & 55.7 & 52.7 & 50.3 & 48.0 & & & $45.3-50.6$ & 1,392 \\
\hline 1998 & 86.8 & 79.5 & 72.8 & 67.7 & 61.7 & 57.0 & 53.0 & 50.5 & 47.6 & 46.3 & 44.1 & & $41.3-46.8$ & 1,288 \\
\hline 1997 & 85.9 & 78.4 & 71.3 & 65.8 & 60.7 & 56.0 & 52.7 & 50.5 & 48.4 & 44.3 & 41.6 & 40.4 & $37.0-43.8$ & 799 \\
\hline
\end{tabular}

Table 6.8. Unadjusted KM survival of incident patients, $1997-2008$ cohort for patients aged $\geqslant 65$

\begin{tabular}{|c|c|c|c|c|c|c|c|c|c|c|c|c|c|c|}
\hline Cohort & 1 year & 2 year & 3 year & 4 year & 5 year & 6 year & 7 year & 8 year & 9 year & 10 year & 11 year & 12 year & $\begin{array}{l}95 \% \text { CI for } \\
\text { latest year }\end{array}$ & $\mathrm{N}$ \\
\hline 2008 & 75.8 & & & & & & & & & & & & $74.2-77.2$ & 3,248 \\
\hline 2007 & 74.9 & 61.1 & & & & & & & & & & & $59.4-62.7$ & 3,211 \\
\hline 2006 & 72.6 & 59.4 & 48.5 & & & & & & & & & & $46.7-50.2$ & 3,179 \\
\hline 2005 & 72.9 & 58.7 & 46.7 & 37.7 & & & & & & & & & $36.0-39.5$ & 3,093 \\
\hline 2004 & 68.7 & 54.8 & 43.4 & 34.5 & 26.9 & & & & & & & & $25.2-28.6$ & 2,736 \\
\hline 2003 & 69.2 & 53.8 & 42.4 & 32.5 & 24.8 & 19.5 & & & & & & & $17.9-21.2$ & 2,386 \\
\hline 2002 & 66.1 & 51.5 & 40.9 & 32.6 & 25.2 & 19.0 & 14.7 & & & & & & $13.2-16.2$ & 2,182 \\
\hline 2001 & 67.2 & 52.1 & 39.4 & 30.4 & 23.0 & 17.2 & 13.1 & 10.0 & & & & & $8.7-11.5$ & 1,866 \\
\hline 2000 & 66.3 & 53.0 & 40.3 & 29.3 & 22.9 & 18.3 & 14.2 & 10.3 & 7.9 & & & & $6.6-9.4$ & 1,519 \\
\hline 1999 & 66.2 & 50.8 & 38.6 & 29.0 & 21.7 & 15.6 & 11.3 & 8.9 & 7.1 & 5.8 & & & $4.6-7.2$ & 1,269 \\
\hline 1998 & 63.8 & 46.8 & 36.2 & 27.4 & 20.5 & 14.7 & 10.6 & 7.4 & 5.3 & 4.0 & 3.0 & & $2.1-4.2$ & 1,149 \\
\hline 1997 & 64.2 & 46.5 & 33.5 & 24.1 & 16.3 & 11.5 & 7.8 & 6.2 & 4.5 & 3.8 & 2.8 & 2.1 & $1.1-3.5$ & 590 \\
\hline
\end{tabular}


Table 6.9. Unadjusted KM survival of incident patients, 1997-2008 cohort for patients of all ages

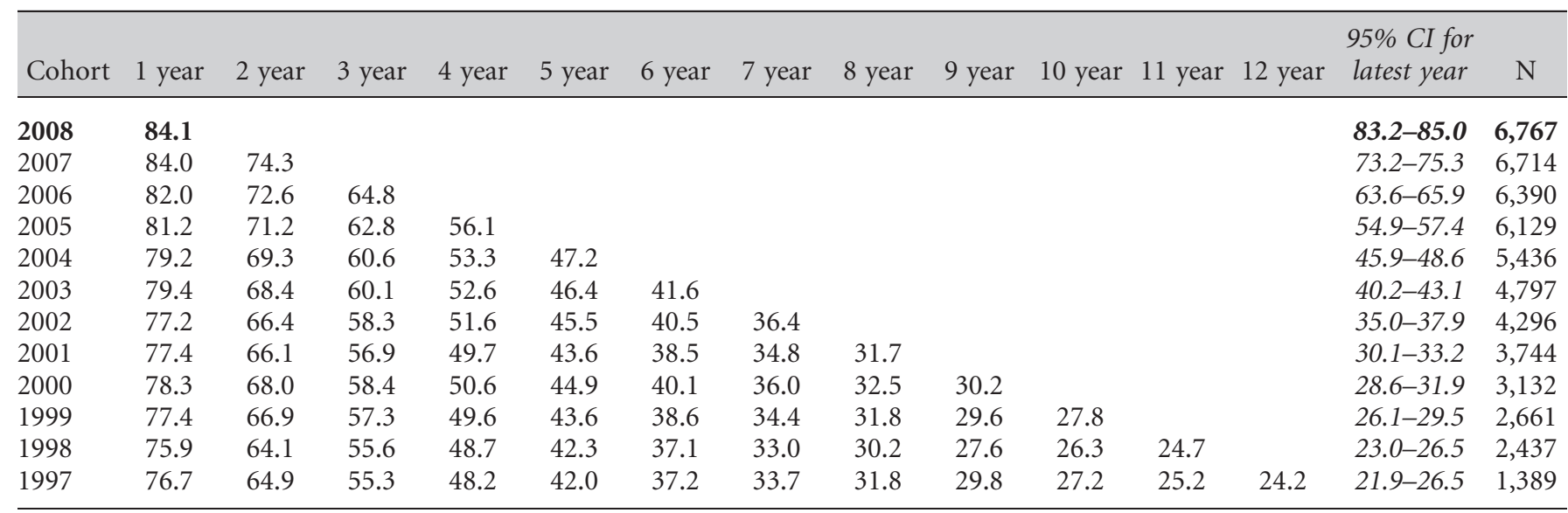

to last year whilst there continued to be an improvement in longer term survival of patients on RRT. There was a steep decline in survival with advancing age (figures 6.2 and 6.3).

There was a curvilinear increase in death rate per 1,000 patient years with age, shown in figure 6.3 for the period one year after 90 days. There were no significant differences between the UK countries.

The effect of censoring age related survival at the time of transplantation

The KM long term survival curves published in all reports prior to the previous 3 years were censored at the time of transplantation. This was not made clear in the description of methodology and was misleading as

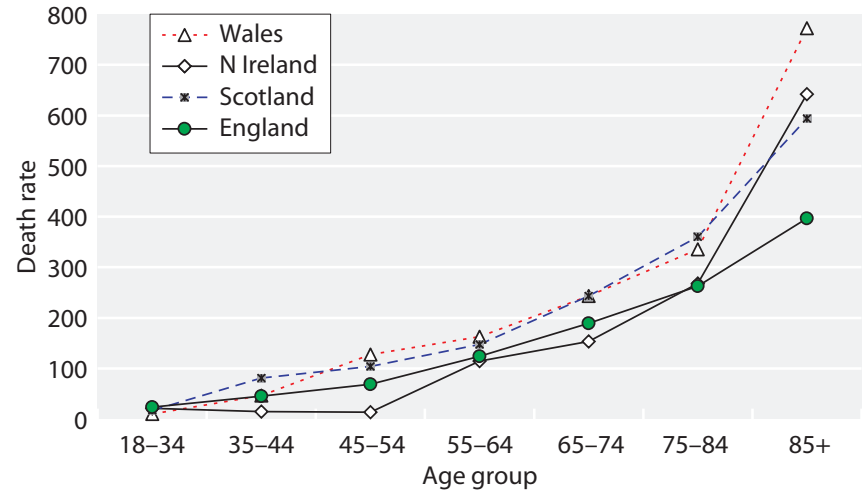

Fig. 6.3. One year after 90 days death rate per 1,000 patients years by UK country and age group for incident patients, 2005-2008 cohort

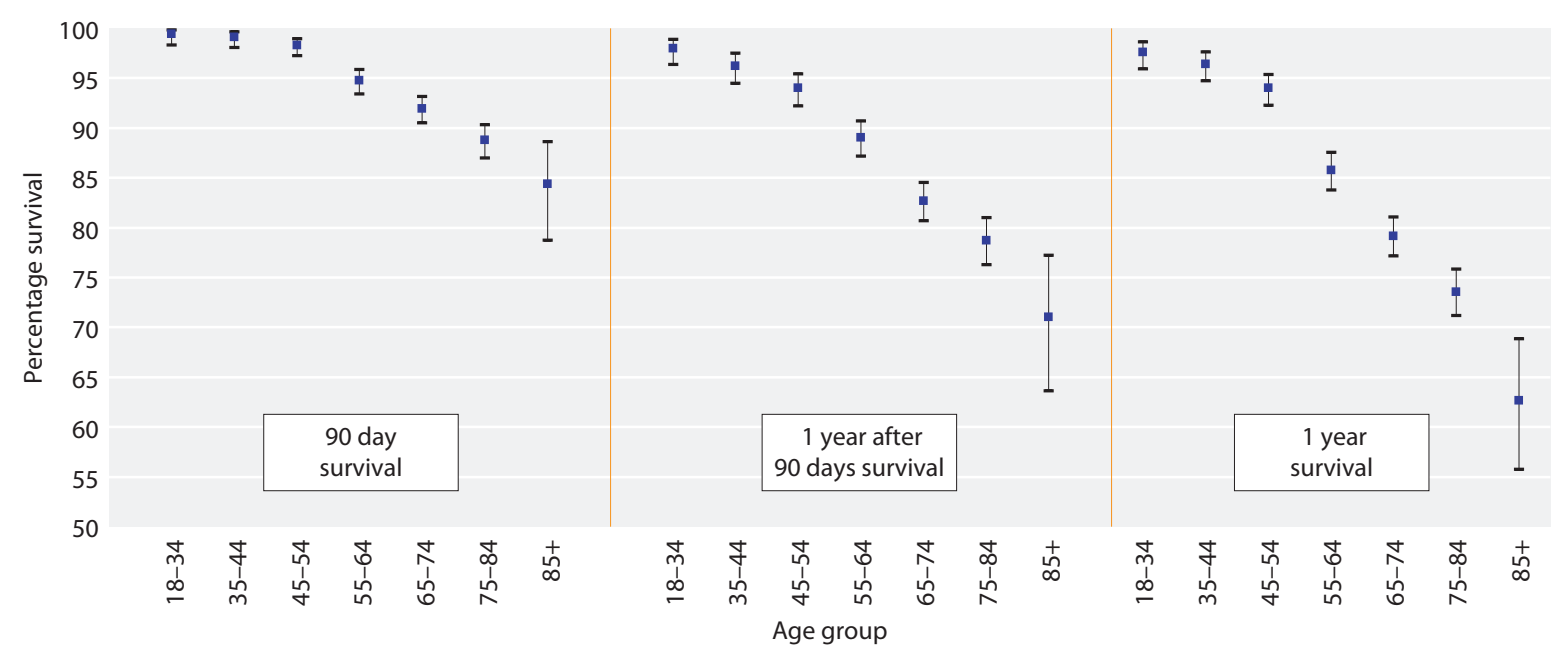

Fig. 6.2. Unadjusted survival of all incident patients by age band, 2008 cohort 

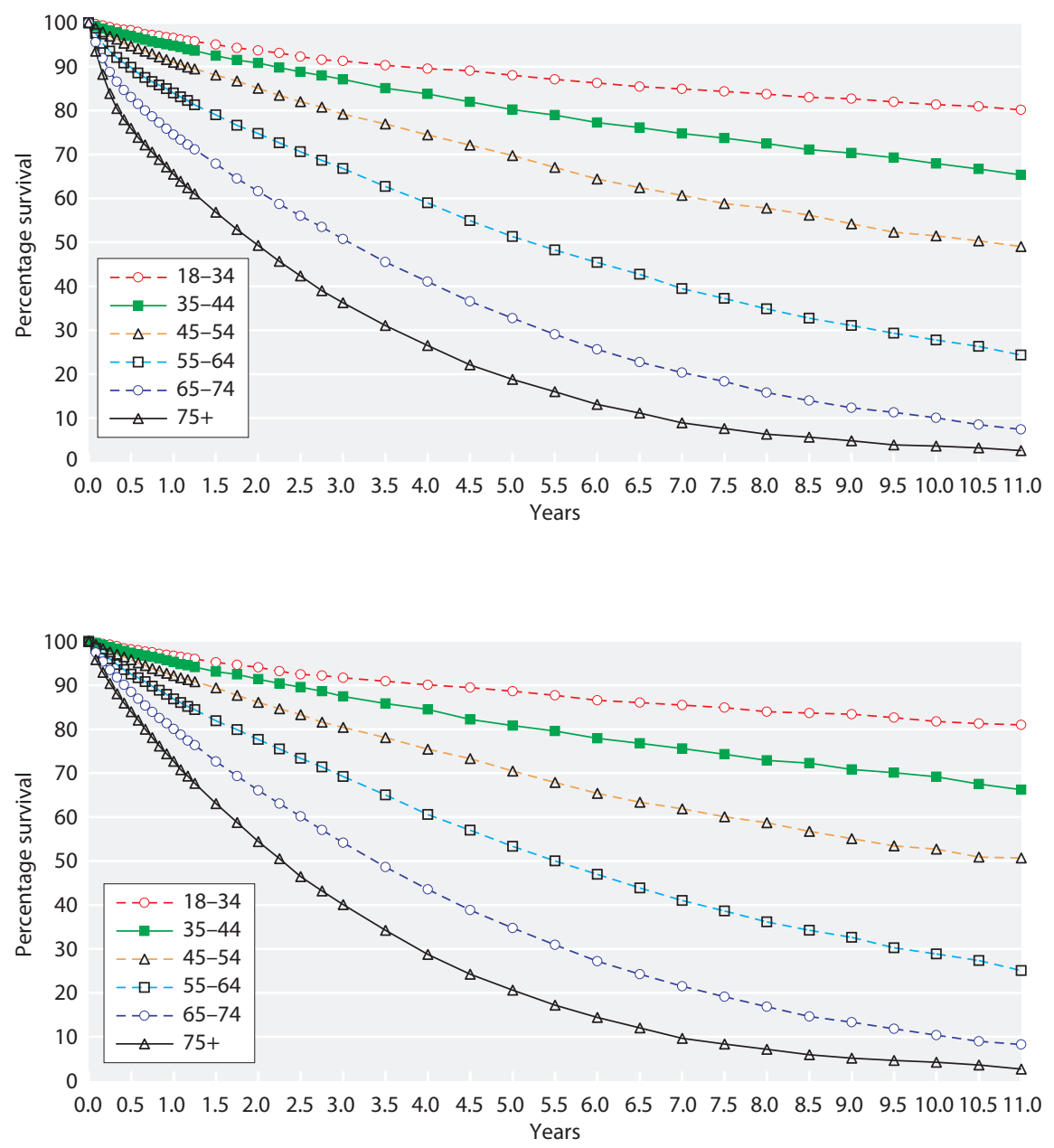

Fig. 6.4. Kaplan-Meier survival of incident patients 1998-2008 cohort (from day 0 ), without censoring at transplantation
Fig. 6.5. Kaplan-Meier survival of incident patients 1998-2008 cohort (from day 90), without censoring at transplantation it made the longer term outcomes of younger patients (who are more likely to have undergone transplantation) appear worse than was actually the case. This is because only those younger patients remaining on dialysis (who may have more comorbidity than those transplanted) will have been included in the censored survival analysis. Without censoring, the 10 year survival for patients aged $18-34$ years is $81.3 \%$ (figure 6.4 ), which contrasts with a $56.4 \%$ survival if censoring at the time of transplantation (data not shown). For more detailed information on this effect, refer to the 2008 Report chapter 7 Survival [7].

From figure 6.4 , it can be seen that $50 \%$ of patients starting RRT aged 50 survived for 10.5 years, $50 \%$ of patients starting aged 60 survived for 5 years and 50\% of patients starting aged 70 survived for 3 years.

Figure 6.5 shows the survival of incident patients, excluding those who died within the first 90 days and shows that $50 \%$ of patients aged 60 survived for 5.5 years and $50 \%$ of patients aged 70 survived for 3.5 years.
Age and hazard of death by age in the first 12 months

Figure 6.6 shows the monthly hazard of death from the 1st day of starting RRT by age, which falls sharply during the first 3-4 months particularly for older

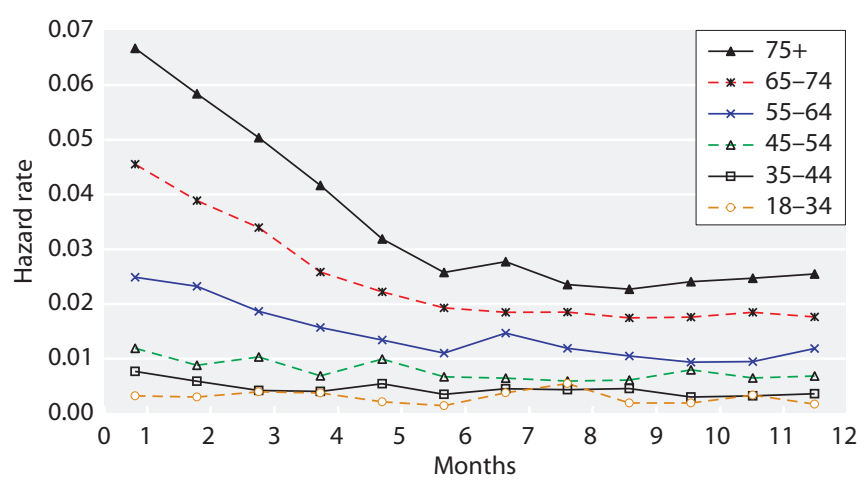

Fig. 6.6. First year monthly hazard of death, by age band 19972008 combined incident cohort 


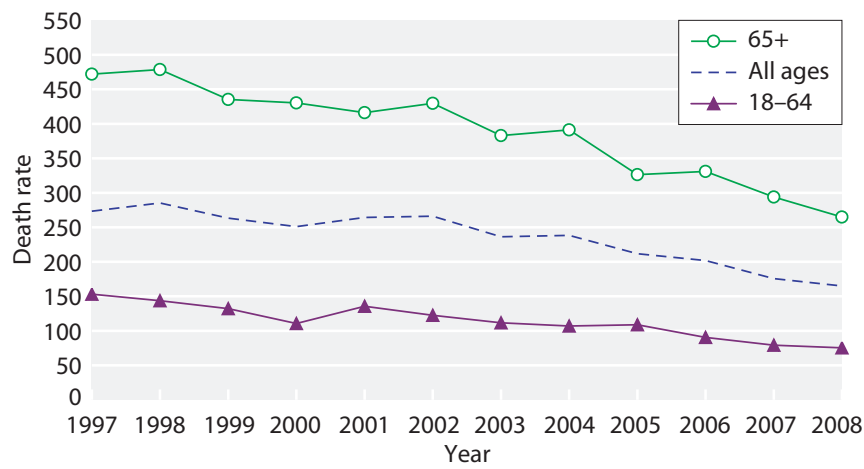

Fig. 6.7. One-year incident death rate per 1,000 patient years for all age groups

patients. In renal registries that receive details on all patients starting RRT from day zero, this difference in the change in hazard of death between the age groups will affect proportionality in any Cox model analysis that uses data starting from day zero and combines these different aged cohorts. This is why survival from day 90 is often used by other countries. Both are presented here to demonstrate this phenomenon of early deaths.

The hazard of death for each 10 year increase in patient age (unadjusted for primary renal disease) is shown in table 6.6. The difference in the hazard of death in the first 90 days and in the year after day 90 has been increasing over time (data not shown). This could reflect greater access to RRT for older and possibly more comorbid patients in recent years.

\section{Changes in survival from 1997-2008}

The 1st year death rate per 1,000 patient years is shown in figure 6.7. There was a continued fall in death rate in the 65 years and over age group to 265

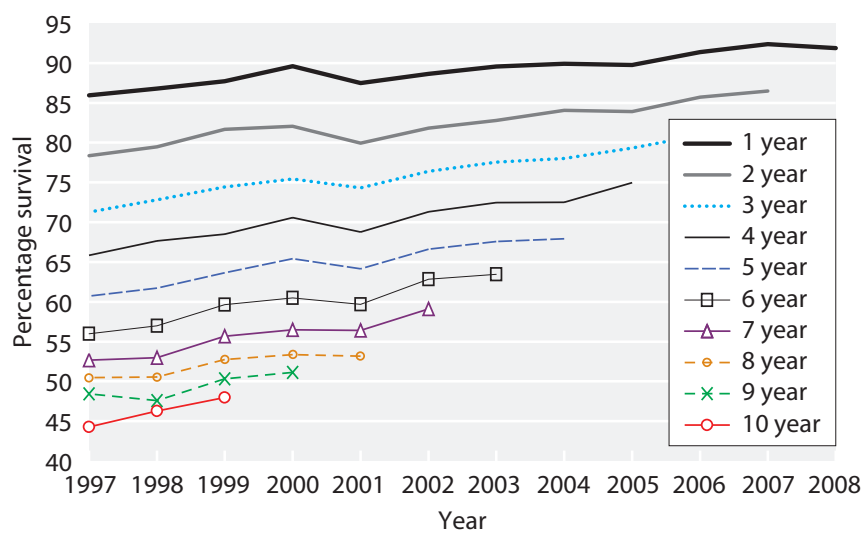

Fig. 6.8. Change in KM long term survival by year of starting RRT; for incident patients aged $18-64$ years

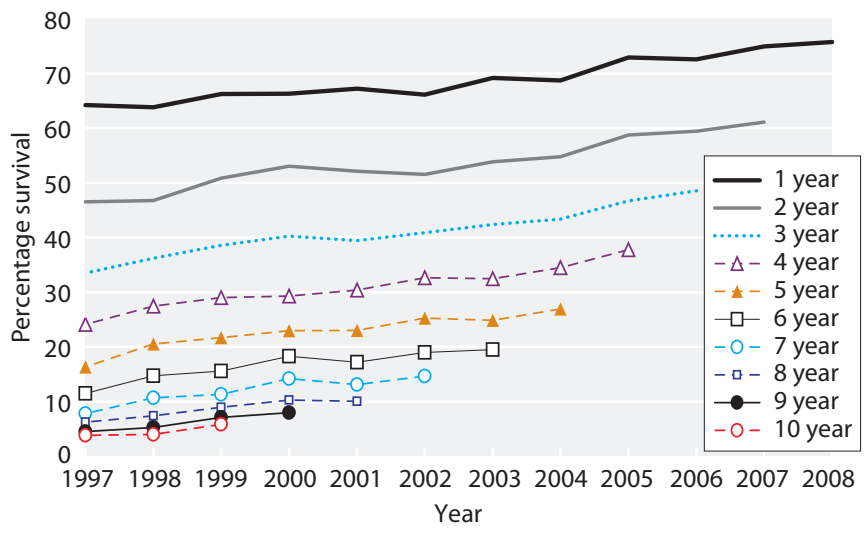

Fig. 6.9. Change in KM long term survival by year of starting RRT; for incident patients aged $\geqslant 65$ years

per 1,000 patient years in 2008 from 294 per 1,000 patient years in 2007 and 331 per 1,000 patient years in 2006. In the under 65 year age group the fall in death rate also continued: from 90 per 1,000 patient years in 2006 to 75 per 1,000 patient years in 2008 .

It is important to note that these death rates are not directly comparable with those produced by the USRDS Registry, as the UK data include the first 90 day period when the death rates are higher than subsequent time periods.

The unadjusted KM survival analyses (tables 6.7 and 6.8, figures 6.8 and 6.9) and annual death rates show a large improvement in 1 to 12 year survival across the time periods for both those under and those aged 65 years and over. One year survival amongst patients aged less than 65 years at start of RRT has improved from $85.9 \%$ in 1997 to $91.9 \%$ in 2008 .

\section{Change in survival on renal replacement therapy by vintage}

RRT patients in the UK continued to show no evidence of a worsening prognosis with time on RRT (vintage). Figure 6.10 demonstrates this clearly for all patients. In the older age groups, there were decreasing numbers remaining alive beyond 7 years accounting for the increased variability seen. Figures 6.11 and 6.12 show these data for the non-diabetic and diabetic patients respectively.

Time trend changes in incident patient survival, 1999-2008

The time trend changes are shown in figure 6.13. The left hand plot, which includes only those centres that have been sending data continuously since 1999, shows a similar improvement in survival to the plot in which data from all renal centres is analysed. 


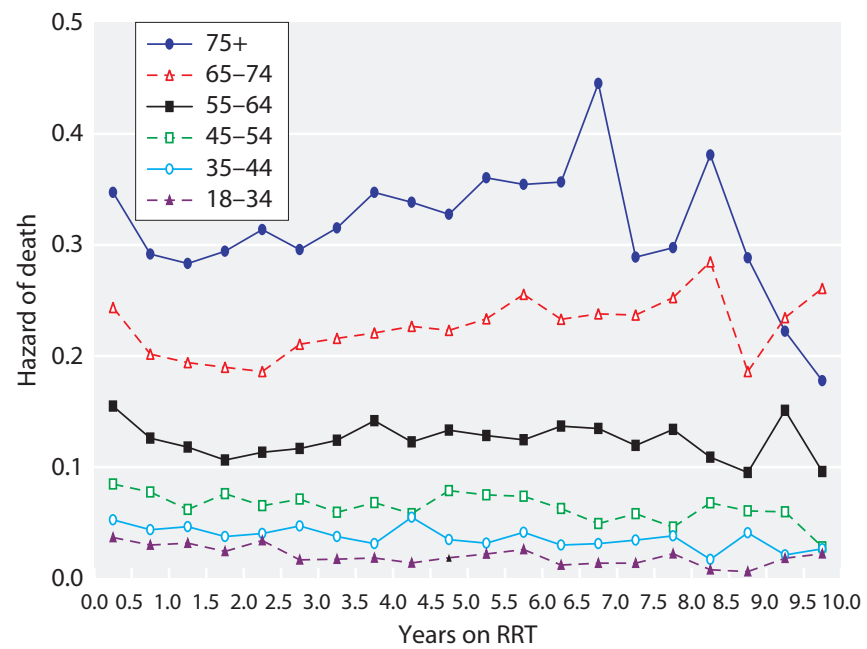

Fig. 6.10. Six monthly hazard of death, by vintage and age band, 1997-2008 incident cohort after day 90

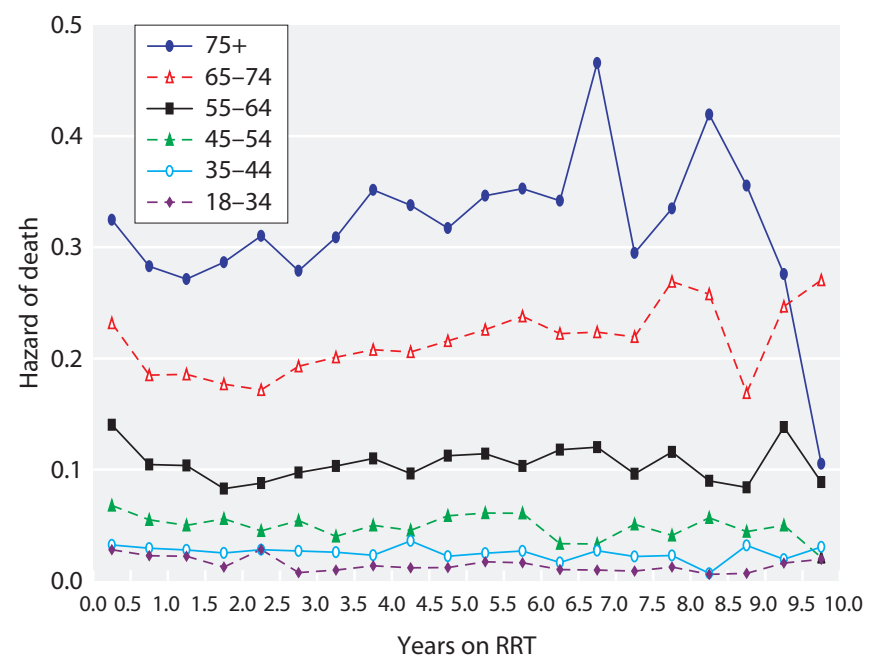

Fig. 6.11. Six monthly hazard of death, by vintage and age band, 1997-2008 non-diabetic incident cohort after day 90

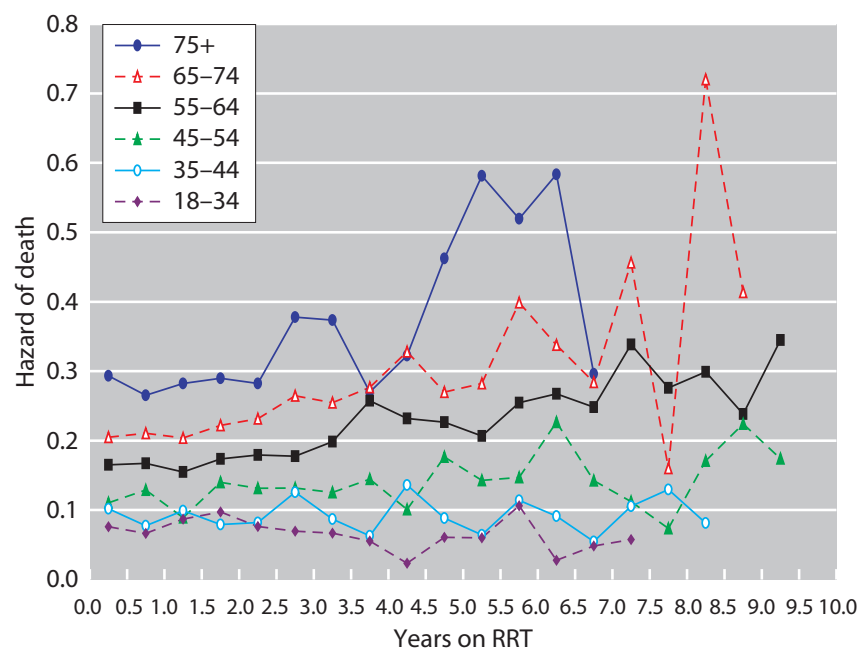

Fig. 6.12. Six monthly hazard of death, by vintage and age band, 1997-2008 diabetic incident cohort after day 90

\section{Analysis of centre variability in 1 year after 90 days survival}

The one year after 90 day survival for the 2008 incident cohort is shown in figure 6.14 for each renal centre. The tables for these data and for 90 day survival are given in appendix 1 at the end of this chapter (tables 6.24 and 6.25). The age-adjusted individual centre survival for each of the last 10 years can also be found in appendix 1, table 6.26 .

In the analysis of 2008 survival data, some of the smaller centres had wide confidence intervals (figure 6.14). This was addressed by including a larger cohort across several years, which will also assess sustained performance. Similar to previous years, this is shown as a rolling 4 year cohort, with the data in this report for the 4 year period 2005 to 2008. These data are

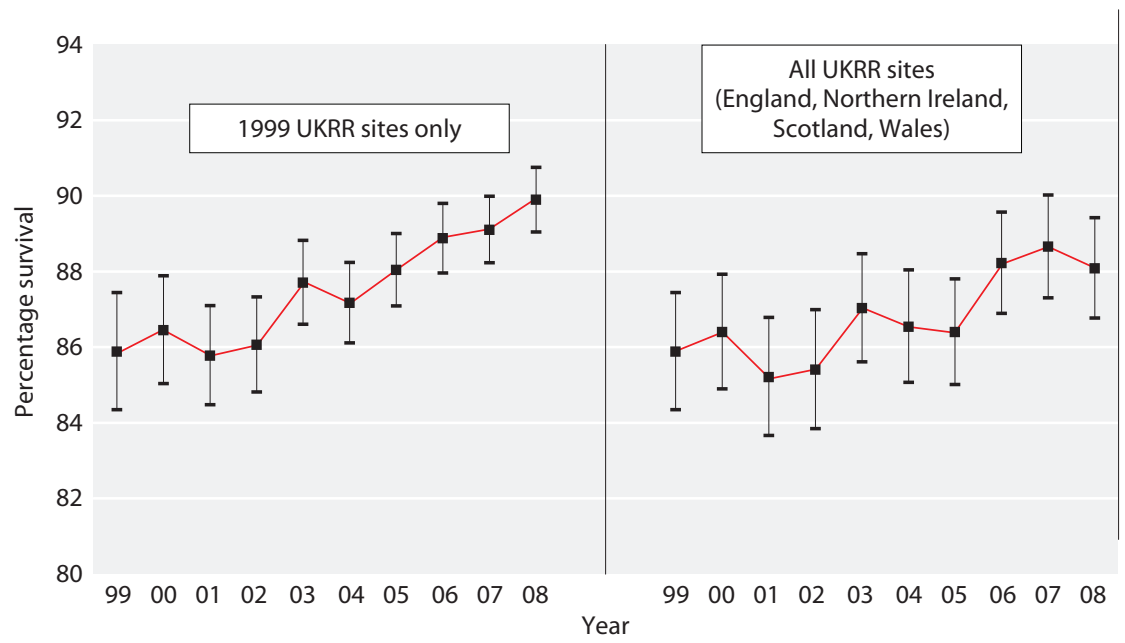

Fig. 6.13. Change in one-year after 90 day survival, 1999-2008 (adjusted to age 60) Showing $95 \%$ confidence intervals

Castledine/Steenkamp/Feest/Tomson 


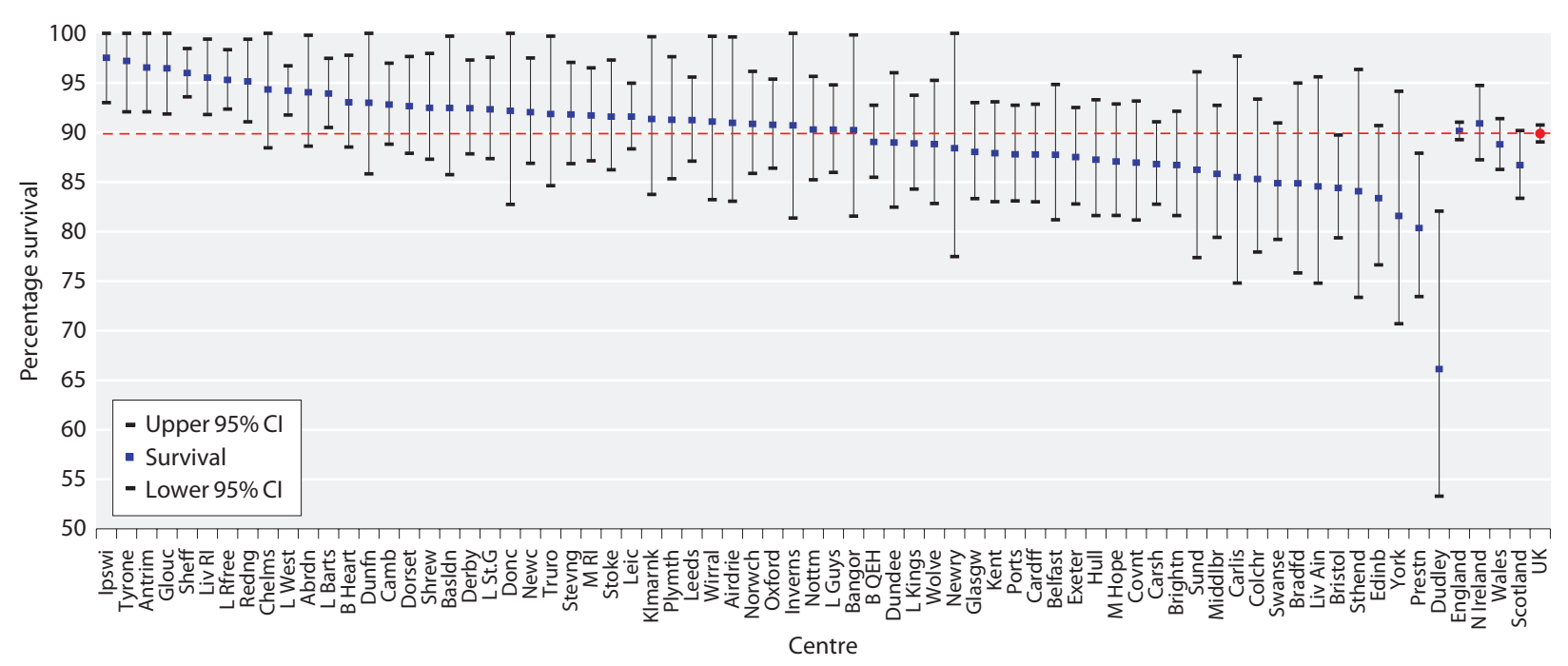

Fig. 6.14. Survival one-year after 90 days, adjusted to age 60, 2008 cohort

presented as a funnel plot in figure 6.15. For any size of incident cohort (x-axis) one can identify whether any given survival rate ( $y$-axis) falls within plus or minus 2 standard deviations (SDs) from the national mean (solid lines, 95\% limits) or 3 SDs (dotted lines, 99.9\% limits). Table 6.10 allows centres to be identified on this graph by finding the number of patients treated by the centre and then looking up this number on the $\mathrm{x}$-axis. These data have not been adjusted for any patient related factor except age (i.e. not comorbidity, primary renal disease or ethnicity) and have not been censored at transplantation, so the effect of differing centre rates of transplantation was not taken into account.

There are known regional differences in the life expectancy of the general population within the UK

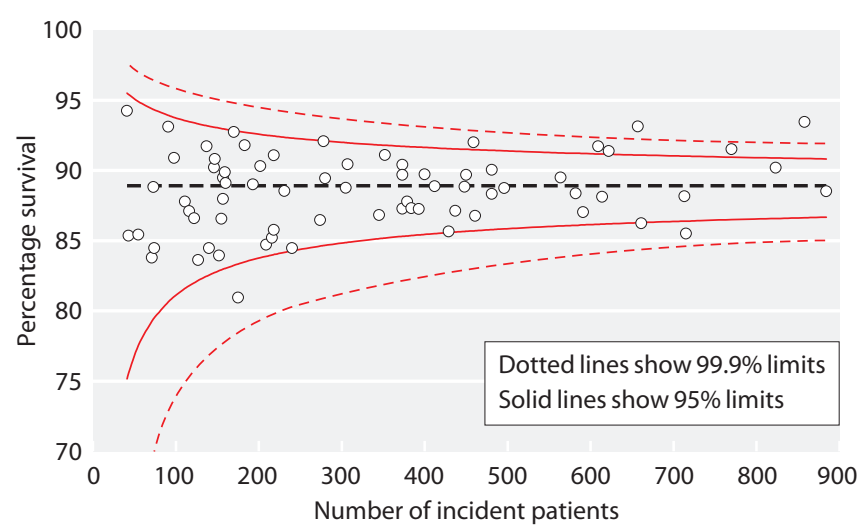

Fig. 6.15. Funnel plot for age adjusted 1 year after 90 days survival, 2005-2008 cohort
[8]. Table 6.11 shows differences in life expectancy between the UK countries. These differences in life expectancy are not accounted for in these analyses and are likely to be one of the reasons behind the variation in survival between renal centres [9].

\section{Analysis of the impact of adjustment for comorbidity}

on the 1 year after 90 day survival

Comorbidity returns to the UKRR have remained poor. Using the combined incident cohort from 20042008 , it was found that 11 centres had returned comorbidity data for more than $85 \%$ of patients and these centres were included in this analysis. Adjustment was first performed to age 60 , then to the average distribution of primary diagnoses for all 11 centres. Further adjustment was then made to the average distribution of comorbidities present at those centres.

It can be seen that adjustment for age has the largest effect, with only minor differences within centres after adjustment for primary renal diagnosis; in two centres (Bradford, Swansea) adjustment for comorbidity had a noticeable effect on adjusted survival (table 6.12 and figure 6.16).

\section{Results of prevalent patient survival analyses}

Table 6.13 shows the one year survival on dialysis, after censoring at the time of transplantation. Patients who have been on dialysis for less than 90 days were excluded. 
Table 6.10. Adjusted (to age 60) 1 year after 90 day survival, 2005-2008 incident cohort

\begin{tabular}{|c|c|c|}
\hline Centre & $\mathrm{N}$ & $\begin{array}{c}1 \text { year after } 90 \text { day } \\
\text { survival } \%\end{array}$ \\
\hline Donc & 41 & 94.2 \\
\hline Ulster & 43 & 85.3 \\
\hline Colchr & 55 & 85.4 \\
\hline D \& Gall & 71 & 83.8 \\
\hline Newry & 73 & 88.8 \\
\hline Clwyd & 74 & 84.5 \\
\hline Tyrone & 91 & 93.1 \\
\hline Wrexm & 98 & 90.9 \\
\hline Carlis & 111 & 87.8 \\
\hline Inverns & 116 & 87.1 \\
\hline Bangor & 122 & 86.6 \\
\hline Liv Ain & 127 & 83.6 \\
\hline Sthend & 137 & 91.7 \\
\hline Dunfn & 140 & 84.5 \\
\hline Antrim & 146 & 90.2 \\
\hline Basldn & 147 & 90.8 \\
\hline Dudley & 152 & 83.9 \\
\hline York & 155 & 86.6 \\
\hline Stoke & 157 & 88.0 \\
\hline Chelms & 157 & 89.5 \\
\hline Truro & 159 & 89.9 \\
\hline Klmarnk & 160 & 89.1 \\
\hline Ipswi & 170 & 92.7 \\
\hline Airdrie & 175 & 80.9 \\
\hline L St.G & 183 & 91.8 \\
\hline Wirral & 193 & 89.0 \\
\hline Shrew & 202 & 90.3 \\
\hline Sund & 209 & 84.7 \\
\hline Abrdn & 216 & 85.2 \\
\hline Glouc & 218 & 91.1 \\
\hline Dundee & 218 & 85.8 \\
\hline Dorset & 231 & 88.5 \\
\hline Bradfd & 240 & 84.5 \\
\hline Plymth & 274 & 86.5 \\
\hline Derby & 278 & 92.1 \\
\hline M RI & 280 & 89.4 \\
\hline
\end{tabular}

\begin{tabular}{|c|c|c|}
\hline Centre & $\mathrm{N}$ & $\begin{array}{c}1 \text { year after } 90 \text { day } \\
\text { survival } \%\end{array}$ \\
\hline Wolve & 305 & 88.8 \\
\hline Kent & 307 & 90.4 \\
\hline Middlbr & 345 & 86.8 \\
\hline Redng & 352 & 91.1 \\
\hline Belfast & 373 & 90.4 \\
\hline Norwch & 373 & 89.7 \\
\hline Edinb & 373 & 87.3 \\
\hline Covnt & 379 & 87.8 \\
\hline Stevng & 384 & 87.3 \\
\hline Newc & 393 & 87.2 \\
\hline B Heart & 400 & 89.7 \\
\hline Hull & 412 & 88.9 \\
\hline Swanse & 429 & 85.7 \\
\hline Exeter & 437 & 87.1 \\
\hline Brightn & 448 & 88.8 \\
\hline Liv RI & 450 & 89.7 \\
\hline Camb & 459 & 92.0 \\
\hline Prestn & 461 & 86.8 \\
\hline Nottm & 481 & 90.0 \\
\hline M Hope & 481 & 88.3 \\
\hline L Kings & 496 & 88.7 \\
\hline Oxford & 564 & 89.5 \\
\hline Leeds & 582 & 88.4 \\
\hline Ports & 591 & 87.0 \\
\hline L Guys & 609 & 91.7 \\
\hline Bristol & 614 & 88.1 \\
\hline Sheff & 622 & 91.4 \\
\hline L Rfree & 657 & 93.1 \\
\hline Glasgw & 661 & 86.2 \\
\hline Carsh & 713 & 88.2 \\
\hline Cardff & 715 & 85.5 \\
\hline L Barts & 770 & 91.5 \\
\hline B QEH & 823 & 90.2 \\
\hline L West & 858 & 93.4 \\
\hline Leic & 884 & 88.5 \\
\hline
\end{tabular}

Data from centres with $<20$ incident patients are not shown (Derry)

${ }^{\star}$ Data from London West excluded for 2005

Table 6.11. Life expectancy in years in UK countries, 2005-2008 (source ONS)

\begin{tabular}{lccccc}
\hline & \multicolumn{2}{c}{ At birth } & & \multicolumn{2}{c}{ At age 65 } \\
\cline { 2 - 3 } \cline { 5 - 6 } Country & Male & Female & & Male & Female \\
\hline England & 78.3 & 82.3 & & 18.0 & 20.6 \\
N Ireland & 76.8 & 81.4 & & 17.2 & 20.0 \\
Scotland & 75.4 & 80.1 & & 16.5 & 19.1 \\
Wales & 77.2 & 81.6 & & 17.4 & 20.1 \\
UK & $\mathbf{7 7 . 9}$ & $\mathbf{8 2 . 0}$ & & $\mathbf{1 7 . 8}$ & $\mathbf{2 0 . 4}$ \\
\hline
\end{tabular}

Table 6.14 gives the 2009 one-year death rate for prevalent dialysis patients in each UK country. The median age of prevalent patients in Northern Ireland and Wales was higher than those in England and this together with socio-economic reasons probably explains the higher death rate in these two countries.

Table 6.15 gives the 2009 one-year survival for transplanted patients.

Figure 6.17 shows the one year survival of dialysis patients who were alive and receiving dialysis on 1st January 2009. 


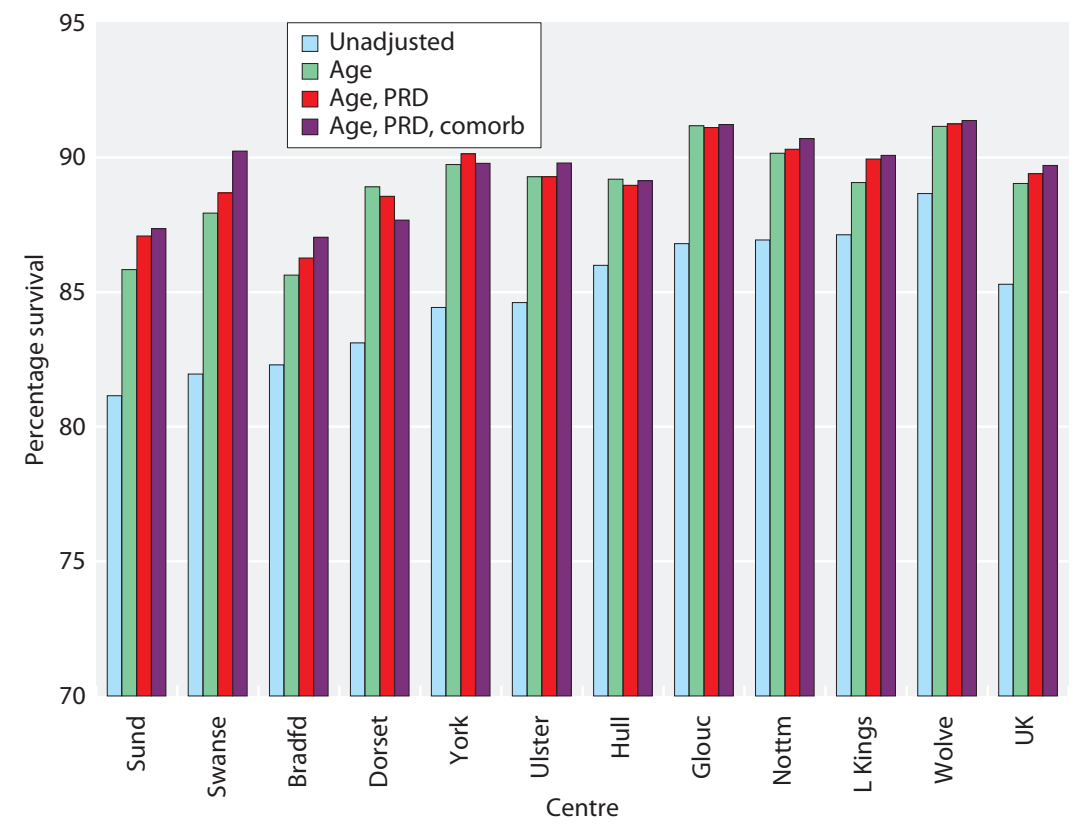

Fig. 6.16. The effect on survival after sequential adjustment for age, PRD and comorbidity, 2004-2008 cohort
One year survival of prevalent dialysis patients by centre The age-adjusted one year survival of dialysis patients in each centre is shown in table 6.13 and is illustrated in figures 6.18 and 6.19; the data for those patients aged $<65$ years and those aged 65 years and over are separated. Figure 6.20 shows the age adjusted data (60 years) and in figure 6.21 as a funnel plot. The solid lines show the 2 standard deviation limits (95\% limits) and the dotted lines the limits for 3 standard deviations (99.9\% limits). With over 70 centres included, it would be expected by chance that 3 centres would fall outside the $95 \%$ ( 1 in 20 ) confidence limits. Table 6.13 allows centres to be identified by finding the number of patients treated by the centre and then looking up this number on the $\mathrm{x}$-axis.

The 2009, one year death rate in prevalent dialysis patients by age band

The death rates on dialysis by age band are shown in figure 6.22. The younger patients included in this analysis are a selected higher risk group, as the similar aged transplanted patients have been excluded. The increase in death rate is non-linear with age: with a 10 year increase in age in the younger patients, the death rate increased by about 20 per 1,000 patient years compared with an increase of 100 per 1,000 patient

Table 6.12. The effect of adjustment for age, PRD and comorbidity on survival, 2004-2008 cohort

\begin{tabular}{lcccc}
\hline & \multicolumn{3}{c}{ \% survival 1 year after 90 days } \\
\cline { 2 - 5 } Centre & Unadjusted & Age adjusted & Age, PRD adjusted & Age, PRD and comorbidity adjusted \\
\hline Ulster & 81.1 & 85.8 & 85.2 & 85.7 \\
Bradfd & 82.0 & 87.9 & 89.1 & 90.6 \\
Dorset & 82.3 & 85.6 & 86.1 & 86.8 \\
York & 83.1 & 88.9 & 89.1 & 88.2 \\
Nottm & 84.4 & 89.7 & 90.4 & 90.0 \\
Hull & 84.6 & 89.3 & 89.7 & 90.3 \\
Glouc & 86.0 & 89.2 & 89.1 & 89.3 \\
L Kings & 86.8 & 91.2 & 91.6 & 91.7 \\
Wolve & 86.9 & 90.2 & 90.9 & 91.2 \\
Sund & 87.1 & 89.1 & 91.4 & 90.1 \\
Swanse & 88.7 & 91.2 & $\mathbf{8 9 . 5}$ & 91.5 \\
All centres & $\mathbf{8 5 . 3}$ & $\mathbf{8 9 . 0}$ & & $\mathbf{8 9 . 8}$ \\
\hline
\end{tabular}

\footnotetext{
${ }^{\star}$ Centres included if $>85 \%$ comorbidity data available
} 


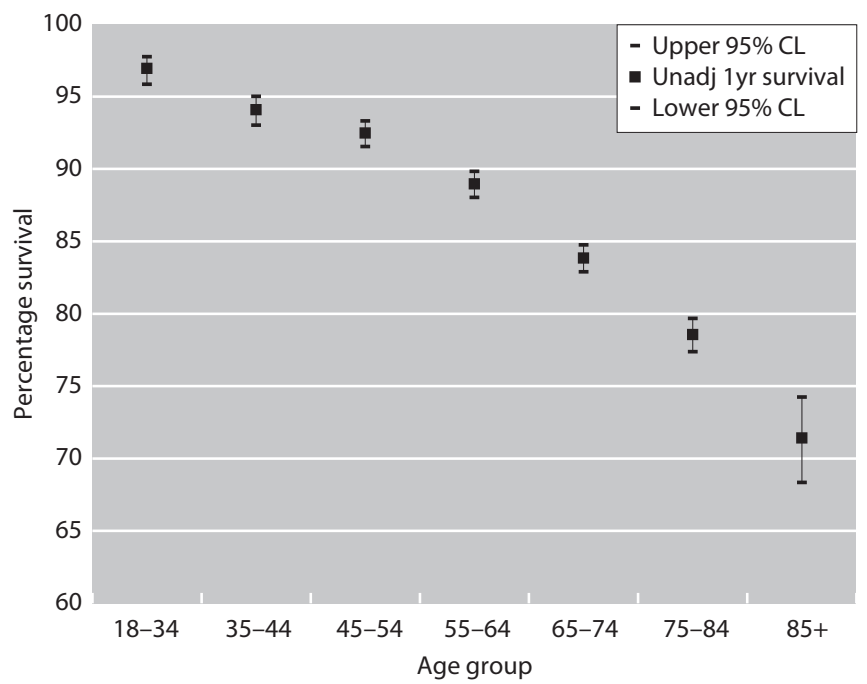

Fig. 6.17. One year survival of prevalent dialysis patients in different age groups, 2009

Table 6.13. One year survival of prevalent dialysis patients in each centre (adjusted to age 60), 2009

\begin{tabular}{|c|c|c|c|c|}
\hline Centre & $\mathrm{N}$ & $\begin{array}{c}\text { Adjusted } \\
1 \text { year survival }\end{array}$ & $\begin{array}{l}\text { Lower } \\
95 \% \text { CI }\end{array}$ & $\begin{array}{c}\text { Upper } \\
95 \% \text { CI }\end{array}$ \\
\hline Abrdn & 229 & 89.6 & 85.9 & 93.4 \\
\hline Airdrie & 166 & 85.6 & 80.6 & 91.0 \\
\hline Antrim & 147 & 89.6 & 85.5 & 94.0 \\
\hline B Heart & 422 & 90.6 & 88.1 & 93.2 \\
\hline B QEH & 948 & 90.2 & 88.4 & 92.0 \\
\hline Bangor & 100 & 84.5 & 78.4 & 91.0 \\
\hline Basldn & 163 & 92.4 & 88.9 & 96.1 \\
\hline Belfast & 298 & 87.4 & 84.0 & 91.0 \\
\hline Bradfd & 203 & 85.4 & 80.8 & 90.2 \\
\hline Brightn & 412 & 87.6 & 84.8 & 90.4 \\
\hline Bristol & 503 & 84.9 & 82.1 & 87.8 \\
\hline Camb & 444 & 90.4 & 88.0 & 92.9 \\
\hline Cardff & 563 & 86.8 & 84.3 & 89.4 \\
\hline Carlis & 97 & 81.3 & 74.3 & 88.9 \\
\hline Carsh & 767 & 89.3 & 87.4 & 91.3 \\
\hline Chelms & 140 & 85.7 & 80.7 & 91.0 \\
\hline Clwyd & 76 & 87.8 & 81.3 & 94.9 \\
\hline Colchr & 101 & 90.9 & 86.1 & 95.9 \\
\hline Covnt & 372 & 90.9 & 88.3 & 93.6 \\
\hline D \& Gall & 64 & 88.2 & 81.6 & 95.4 \\
\hline Derby & 316 & 90.9 & 88.0 & 93.8 \\
\hline Derry & 60 & 90.8 & 84.5 & 97.6 \\
\hline Donc & 90 & 83.9 & 77.3 & 91.0 \\
\hline Dorset & 238 & 89.8 & 86.5 & 93.2 \\
\hline Dudley & 178 & 88.9 & 84.7 & 93.4 \\
\hline Dundee & 190 & 93.8 & 90.9 & 96.8 \\
\hline Dunfn & 142 & 87.6 & 82.8 & 92.6 \\
\hline Edinb & 339 & 86.5 & 83.1 & 90.1 \\
\hline Exeter & 372 & 85.1 & 82.0 & 88.3 \\
\hline Glasgw & 670 & 88.6 & 86.4 & 90.9 \\
\hline Glouc & 184 & 92.0 & 88.8 & 95.4 \\
\hline Hull & 369 & 87.9 & 84.9 & 91.0 \\
\hline
\end{tabular}

Table 6.13. Continued

\begin{tabular}{|c|c|c|c|c|}
\hline Centre & $\mathrm{N}$ & $\begin{array}{c}\text { Adjusted } \\
1 \text { year survival }\end{array}$ & $\begin{array}{l}\text { Lower } \\
95 \% C I\end{array}$ & $\begin{array}{c}\text { Upper } \\
95 \% C I\end{array}$ \\
\hline Inverns & 120 & 92.2 & 88.0 & 96.5 \\
\hline Ipswi & 148 & 85.1 & 79.8 & 90.7 \\
\hline Kent & 383 & 88.0 & 85.0 & 91.0 \\
\hline Klmarnk & 177 & 88.3 & 84.2 & 92.7 \\
\hline L Barts & 835 & 90.7 & 88.7 & 92.7 \\
\hline L Guys & 554 & 91.3 & 89.1 & 93.5 \\
\hline L Kings & 476 & 87.9 & 85.2 & 90.8 \\
\hline L Rfree & 710 & 89.7 & 87.6 & 91.8 \\
\hline L St.G & 259 & 89.9 & 86.7 & 93.2 \\
\hline L West & 1,307 & 92.2 & 90.9 & 93.6 \\
\hline Leeds & 566 & 89.2 & 86.9 & 91.6 \\
\hline Leic & 879 & 88.7 & 86.8 & 90.7 \\
\hline Liv Ain & 118 & 92.2 & 87.9 & 96.7 \\
\hline Liv RI & 474 & 89.2 & 86.5 & 92.0 \\
\hline M Hope & 443 & 88.1 & 85.2 & 91.0 \\
\hline M RI & 497 & 87.4 & 84.6 & 90.4 \\
\hline Middlbr & 304 & 86.9 & 83.5 & 90.4 \\
\hline Newc & 310 & 87.5 & 84.1 & 91.0 \\
\hline Newry & 104 & 94.7 & 91.0 & 98.6 \\
\hline Norwch & 355 & 89.0 & 86.3 & 91.9 \\
\hline Nottm & 478 & 87.9 & 85.2 & 90.6 \\
\hline Oxford & 504 & 89.0 & 86.5 & 91.5 \\
\hline Plymth & 181 & 85.7 & 81.4 & 90.3 \\
\hline Ports & 500 & 89.0 & 86.6 & 91.5 \\
\hline Prestn & 481 & 89.7 & 87.2 & 92.3 \\
\hline Redng & 296 & 92.1 & 89.5 & 94.9 \\
\hline Sheff & 653 & 89.4 & 87.2 & 91.6 \\
\hline Shrew & 210 & 88.3 & 84.3 & 92.4 \\
\hline Stevng & 465 & 90.5 & 88.1 & 92.9 \\
\hline Sthend & 135 & 91.1 & 87.1 & 95.4 \\
\hline Stoke & 321 & 88.3 & 85.1 & 91.6 \\
\hline Sund & 176 & 85.7 & 80.9 & 90.8 \\
\hline Swanse & 397 & 87.6 & 84.8 & 90.5 \\
\hline Truro & 161 & 88.6 & 84.6 & 92.8 \\
\hline Tyrone & 99 & 87.1 & 81.4 & 93.2 \\
\hline Ulster & 94 & 87.5 & 82.0 & 93.2 \\
\hline Wirral & 205 & 90.4 & 86.8 & 94.2 \\
\hline Wolve & 330 & 89.5 & 86.6 & 92.6 \\
\hline Wrexm & 112 & 90.2 & 85.4 & 95.2 \\
\hline York & 145 & 88.0 & 83.4 & 92.9 \\
\hline England & 20,178 & 89.2 & 88.7 & 89.6 \\
\hline N Ireland & 802 & 89.0 & 87.0 & 91.0 \\
\hline Scotland & 2,097 & 88.8 & 87.5 & 90.1 \\
\hline Wales & 1,248 & 87.2 & 85.5 & 88.9 \\
\hline UK & 24,325 & 89.0 & 88.6 & 89.5 \\
\hline
\end{tabular}

Table 6.14. One-year death rate per 1,000 prevalent dialysis patient years in 2009 and median age of prevalent patients by country

\begin{tabular}{lcccc}
\hline & England & N Ireland & Scotland & Wales \\
\hline Death rate & 146 & 155 & 149 & 184 \\
$95 \%$ CI & $140-152$ & $128-187$ & $132-167$ & $160-211$ \\
Median age & 64.5 & 65.9 & 63.7 & 66.4 \\
\hline
\end{tabular}


Table 6.15. One-year survival of prevalent RRT patients in the UK by modality (unadjusted unless stated otherwise)

\begin{tabular}{|c|c|c|c|c|}
\hline Patient group & Patients & Deaths & KM survival & KM 95\% CI \\
\hline \multicolumn{5}{|l|}{ Transplant patients 2009} \\
\hline Censored at dialysis & 20,368 & 487 & 97.6 & $97.3-97.8$ \\
\hline Not censored at dialysis & 20,368 & 524 & 97.4 & $97.2-97.6$ \\
\hline \multicolumn{5}{|l|}{ Dialysis patients 2009} \\
\hline All & 24,325 & 3,216 & 86.2 & $85.8-86.7$ \\
\hline All adjusted age $=60$ & 24,325 & 3,216 & 89.0 & $88.6-89.5$ \\
\hline \multicolumn{5}{|c|}{2 year survival - dialysis patients 2008} \\
\hline All 1/1/2008 (2 year) & 23,496 & 5,766 & 73.5 & $72.9-74.1$ \\
\hline \multicolumn{5}{|l|}{ Dialysis patients 2009} \\
\hline All age $<65$ & 12,438 & 945 & 91.8 & $91.3-92.3$ \\
\hline All age $65+$ & 11,887 & 2,271 & 80.7 & $80.0-81.4$ \\
\hline Non-diabetic $<55$ & 6,045 & 254 & 95.4 & $94.8-95.9$ \\
\hline Non-diabetic 55-64 & 3,600 & 332 & 90.3 & $89.2-91.2$ \\
\hline Non-diabetic 65-74 & 4,448 & 645 & 85.2 & $84.1-86.2$ \\
\hline Non-diabetic 75+ & 4,745 & 1,065 & 77.5 & $76.3-78.7$ \\
\hline Non-diabetic $<65$ & 9,645 & 586 & 93.4 & 92.9-93.9 \\
\hline Diabetic $<65$ & 2,348 & 316 & 85.9 & $84.4-87.3$ \\
\hline Non-diabetic $65+$ & 9,193 & 1,710 & 81.2 & $80.4-82.0$ \\
\hline Diabetic $65+$ & 2,268 & 480 & 78.7 & $77.0-80.3$ \\
\hline
\end{tabular}

$\mathrm{KM}=$ Kaplan Meier survival

Cohorts of patients alive on 1/1/2009 unless indicated otherwise

years in the older age groups. In all age groups these death rates are lower than comparable death rates reported by the USRDS in 2009 [10].

One year survival of prevalent dialysis patients by UK country from 1997 to 2009

Scotland and Wales are showing a continued improvement in the age-adjusted survival on dialysis (figure 6.23) whilst England and Northern Ireland show no change in age-adjusted survival in the past 2 years. The change in prevalent survival by centre over the years 2000 to 2009 is shown in this chapter, appendix 1, table 6.27.

One year survival of prevalent dialysis patients with a primary diagnosis of diabetes from 2000 to 2009

The previously improving age-adjusted survival in patients with diabetic renal disease in the UK has plateaued over the last three years (table 6.16) with no further improvements in survival.

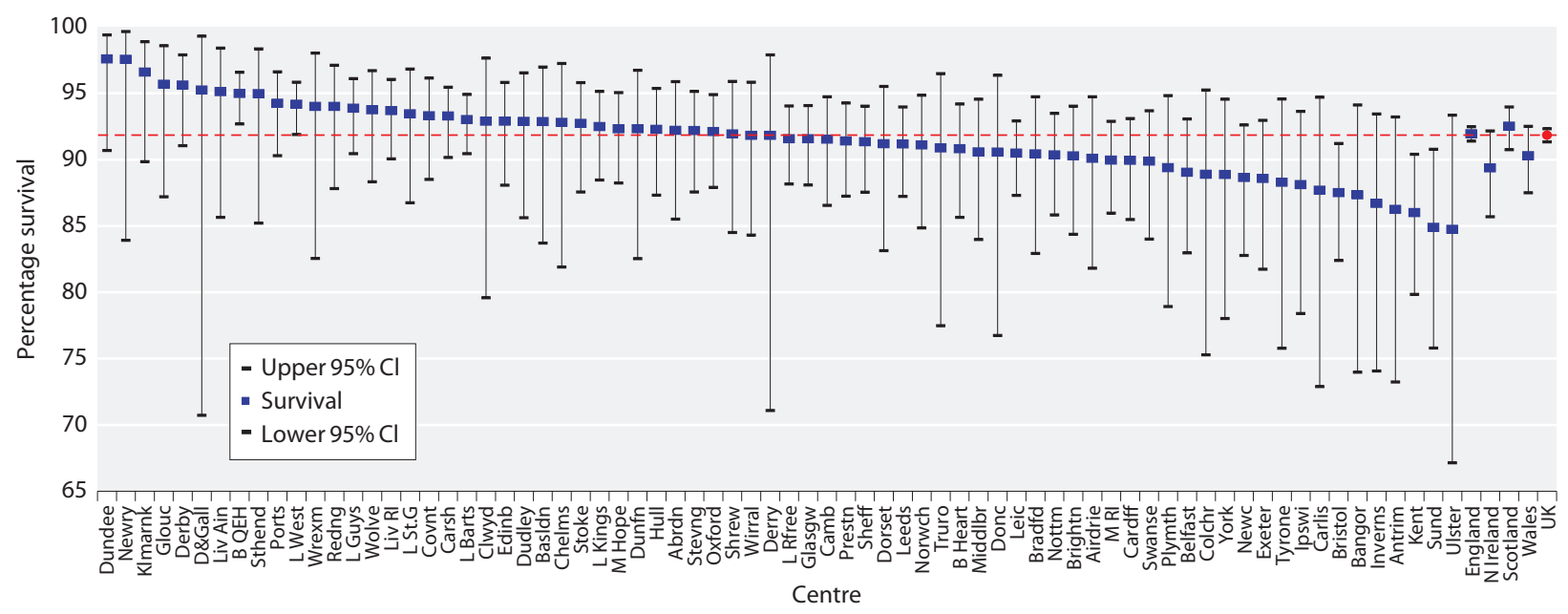

Fig. 6.18. One year survival of prevalent dialysis patients aged under 65 years in each centre, 2009 


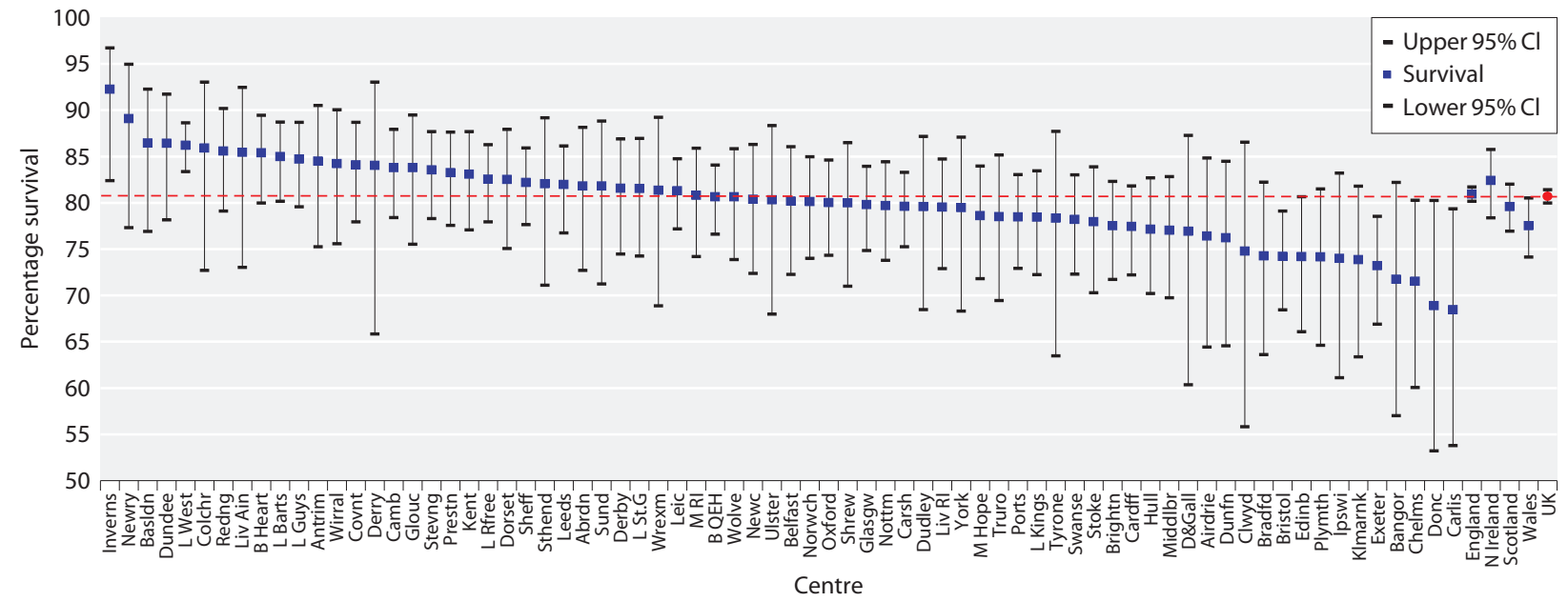

Fig. 6.19. One year survival of prevalent dialysis patients aged 65 years and over in each centre, 2009

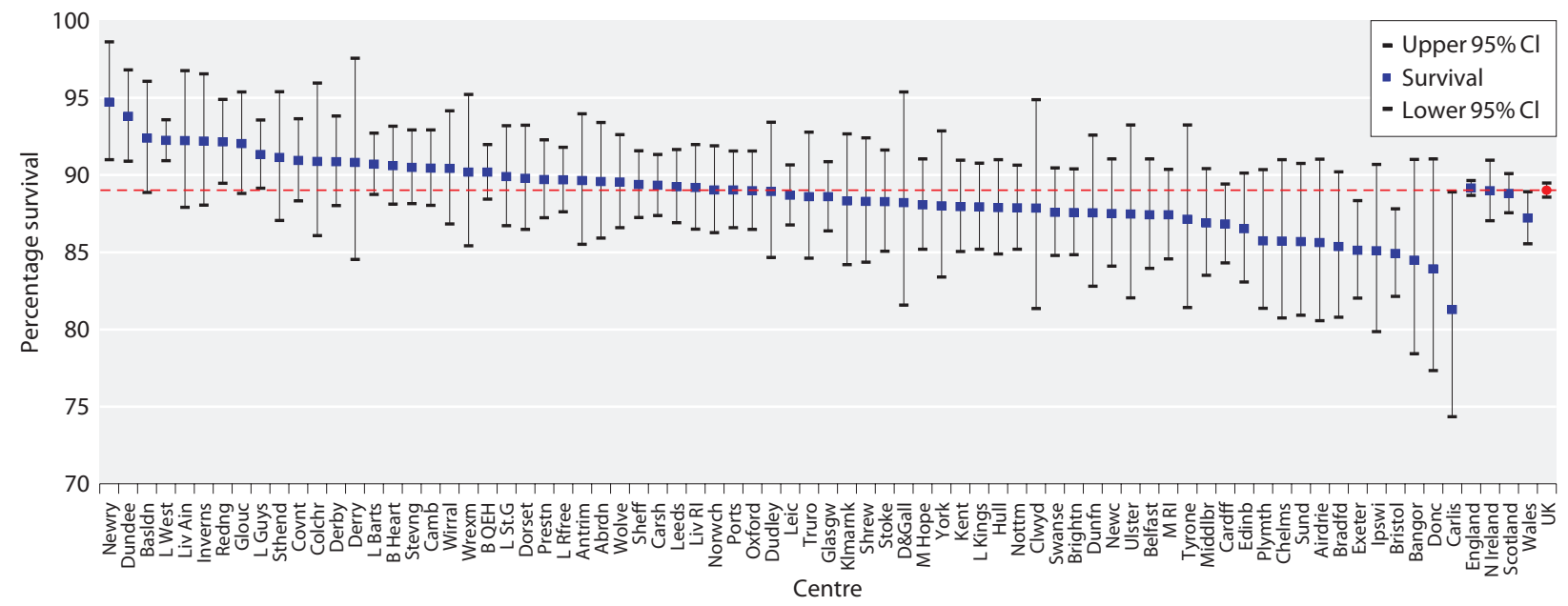

Fig. 6.20. One year survival of prevalent dialysis patients in each centre adjusted to age 60, 2009

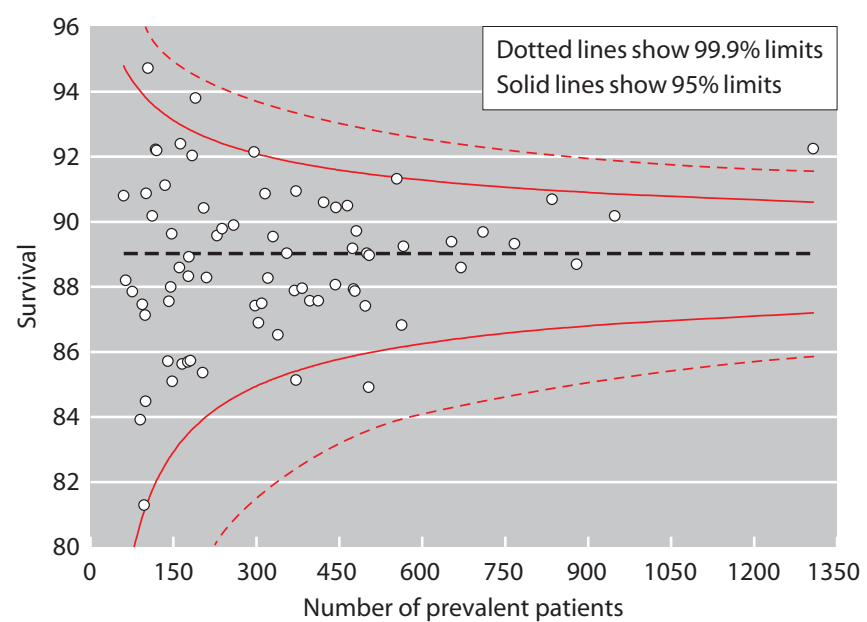

Fig. 6.21. One year funnel plot of prevalent dialysis patients in each centre adjusted to age 60, 2009

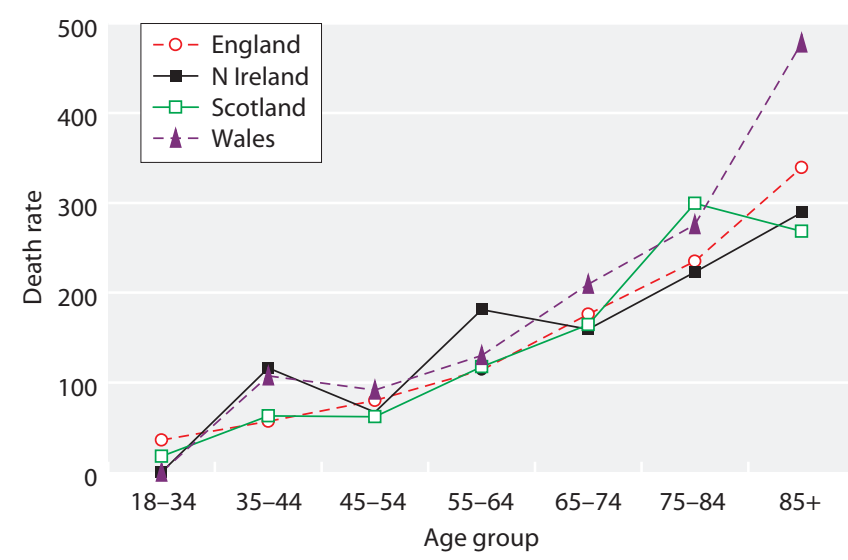

Fig. 6.22. One year death rate per 1,000 patient years by UK country and age group for prevalent dialysis patients, 2009 

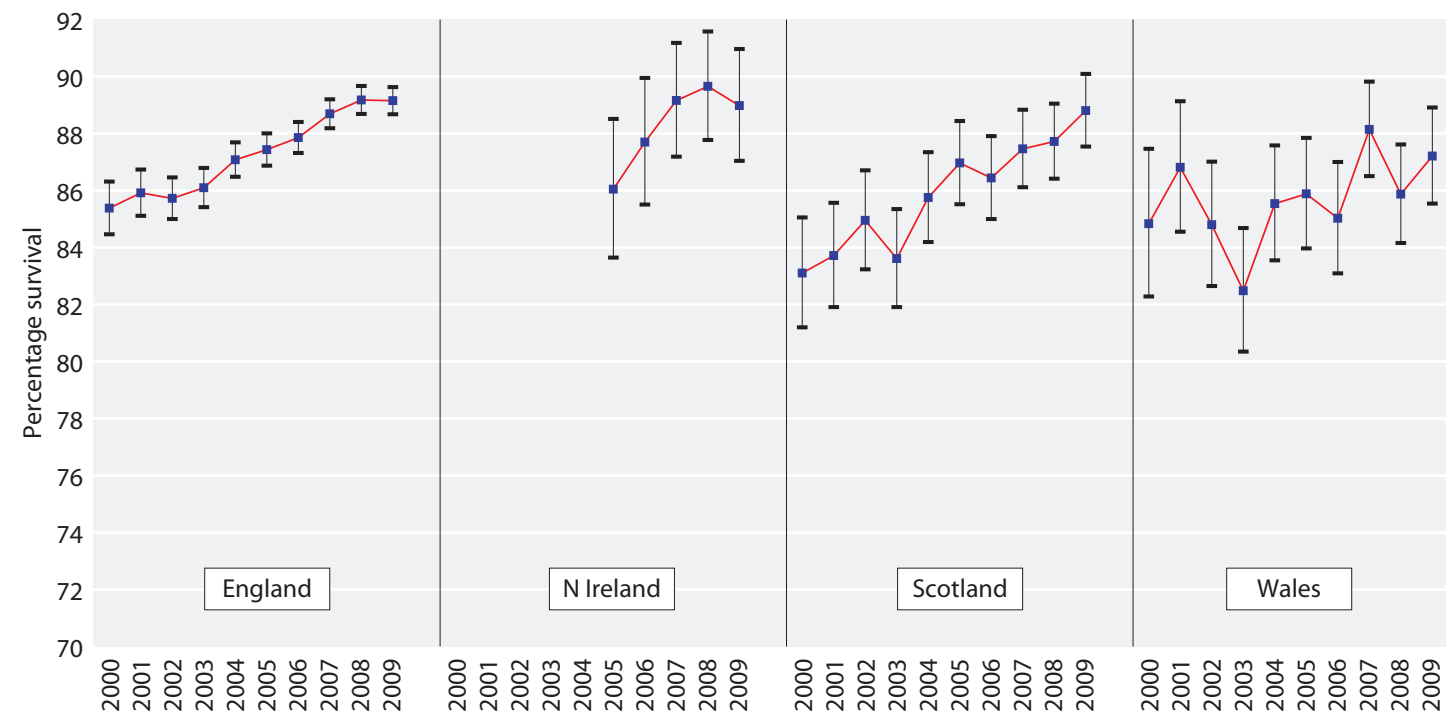

Year

Fig. 6.23. Serial 1 year survival for prevalent dialysis patients by UK country from 2000-2009 adjusted to age 60

Death rate on $R R T$ compared with the UK general population

The death rate compared to the general population is shown in table 6.17. Figure 6.24 shows that the relative risk of death on RRT decreased with age from 19 times that of the general population at age 30 to 34 to 2.4 times the general population at age $85+$. With the reduction in rates of death on RRT over the last 10

Table 6.16. Serial 1 year survival of prevalent dialysis patients with a primary diagnosis of diabetes from 2000-2009

\begin{tabular}{llllllllllll}
\hline Year & 2000 & 2001 & 2002 & 2003 & 2004 & 2005 & 2006 & 2007 & 2008 & 2009 \\
\hline 1 year survival & 76.6 & 77.3 & 78.6 & 77.9 & 80.7 & 82.5 & 81.8 & 84.7 & 83.6 & 83.6 \\
\hline
\end{tabular}

Table 6.17. Death rate by age for all prevalent RRT patients on $1 / 1 / 2009$, compared with the general population and with previous analyses in the 1998-2001 cohort

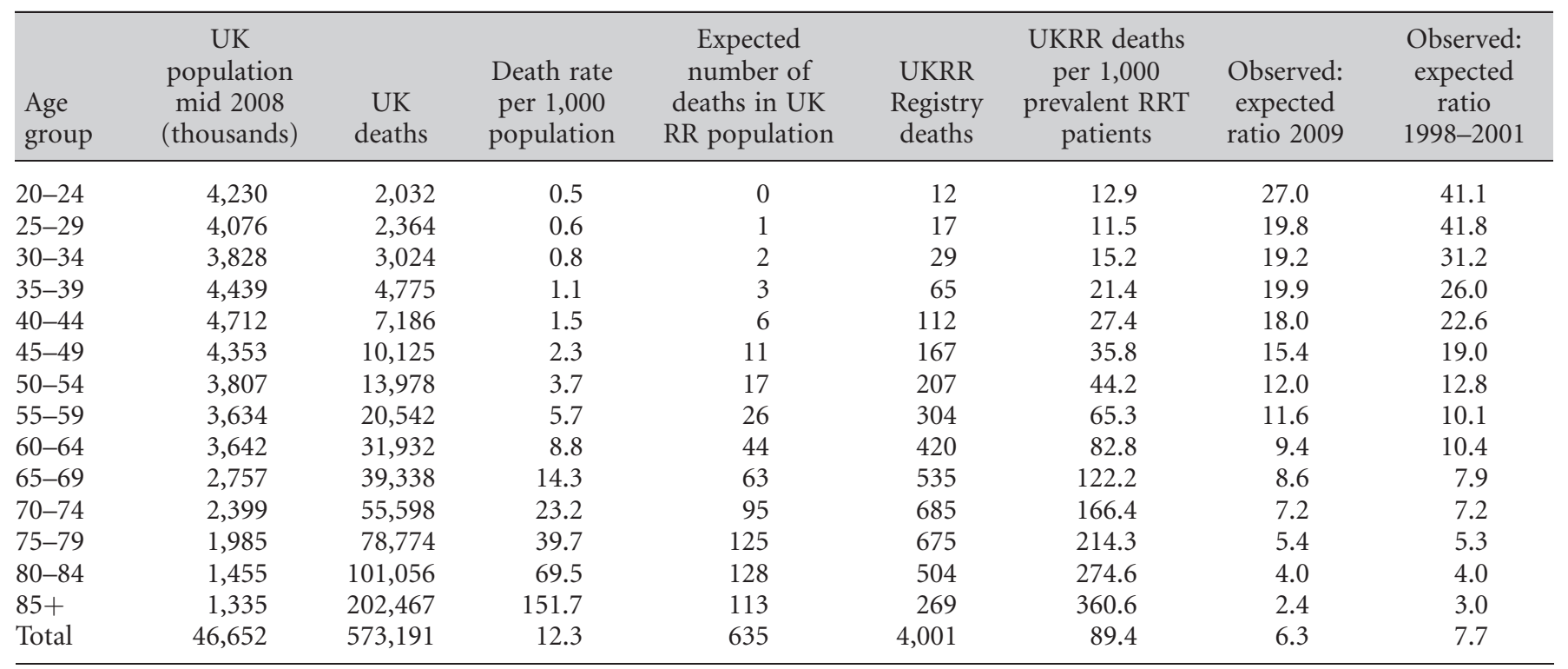




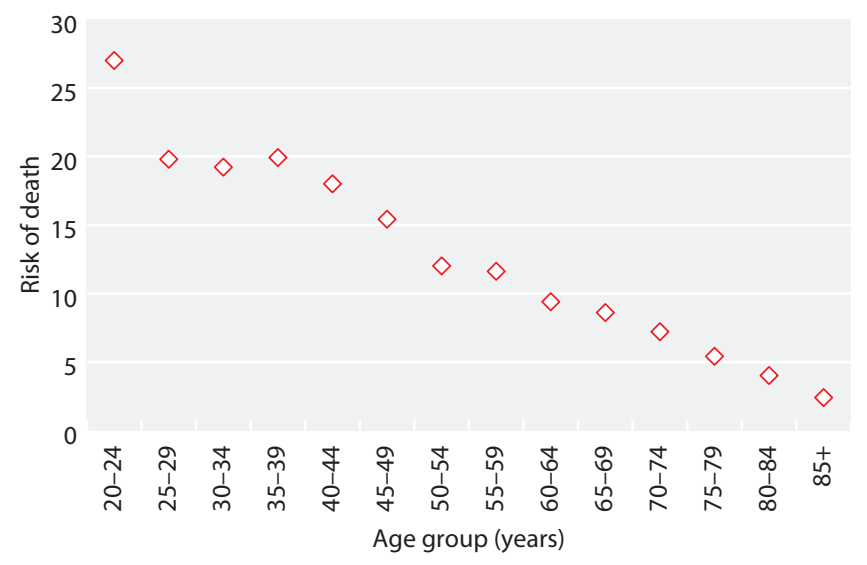

Fig. 6.24. Relative risk of death in all prevalent RRT patients in 2009 compared with the UK general population in 2008 years the age-standardised mortality ratios compared with the general population are falling ( 7.7 in 2001, 6.3 in 2009).

\section{Results of analyses on causes of death}

\section{Data completeness}

Data completeness is shown in table 6.18. Overall, it was less than $50 \%$ and has not improved over the last 5 years. Interpretation of patterns of cause of death must be cautious as it was not known whether non-return was associated with cause. Some centres consistently achieve a very high rate of data return for cause of death because a process is in place to make sure that

Table 6.18. Percentage completeness of EDTA causes of death for incident patients by centre and year of starting RRT

\begin{tabular}{|c|c|c|c|c|c|c|c|c|c|c|}
\hline Centre & 2000 & 2001 & 2002 & 2003 & 2004 & 2005 & 2006 & 2007 & 2008 & 2009 \\
\hline Abrdn & 28.0 & 31.3 & 30.6 & 23.5 & 27.0 & 24.2 & 19.2 & 87.5 & 71.4 & 80.0 \\
\hline Airdrie & 40.0 & 32.6 & 35.7 & 36.1 & 54.5 & 40.0 & 45.0 & 77.8 & 100.0 & 100.0 \\
\hline Antrim & & & & & & 10.0 & 18.2 & 14.3 & 0.0 & 100.0 \\
\hline B Heart & 75.0 & 82.6 & 78.4 & 70.6 & 76.6 & 90.0 & 88.7 & 87.0 & 100.0 & 100.0 \\
\hline B QEH & & & & & 36.7 & 2.2 & 3.0 & 5.8 & 1.7 & 0.0 \\
\hline Bangor & & & 54.2 & 26.3 & 59.3 & 48.1 & 44.0 & 37.5 & 50.0 & 66.7 \\
\hline Basldn & & & & 48.0 & 59.3 & 33.3 & 57.1 & 46.2 & 80.0 & 80.0 \\
\hline Belfast & & & & & & 25.0 & 19.4 & 41.9 & 26.7 & 40.0 \\
\hline Bradfd & & 78.6 & 88.6 & 92.2 & 81.1 & 89.5 & 86.7 & 96.4 & 93.8 & 83.3 \\
\hline Brightn & & & & & 3.8 & 3.3 & 3.5 & 0.0 & 0.0 & 0.0 \\
\hline Bristol & 51.0 & 50.0 & 65.0 & 71.7 & 76.0 & 59.3 & 70.3 & 48.1 & 61.7 & 77.8 \\
\hline Camb & & 0.0 & 0.0 & 0.0 & 0.0 & 4.5 & 5.8 & 2.9 & 0.0 & 6.3 \\
\hline Cardff & 0.0 & 0.0 & 0.8 & 0.0 & 0.0 & 0.0 & 1.1 & 0.0 & 0.0 & 0.0 \\
\hline Carlis & 36.0 & 27.3 & 65.0 & 60.9 & 75.0 & 71.4 & 58.3 & 71.4 & 77.8 & 100.0 \\
\hline Carsh & 3.5 & 2.3 & 0.9 & 0.9 & 0.0 & 0.0 & 1.3 & 0.0 & 0.0 & 0.0 \\
\hline Chelms & & & & & 55.9 & 88.9 & 80.8 & 94.4 & 40.0 & 50.0 \\
\hline Clwyd & & & 12.5 & 0.0 & 11.1 & 6.3 & 63.6 & 50.0 & 100.0 & 0.0 \\
\hline Colchr & & & & & & & & & 0.0 & 0.0 \\
\hline Covnt & 20.0 & 9.2 & 14.3 & 2.1 & 0.0 & 0.0 & 0.0 & 0.0 & 0.0 & 0.0 \\
\hline D \& Gall & 94.0 & 72.2 & 92.3 & 83.3 & 72.7 & 88.2 & 90.9 & 100.0 & 100.0 & 100.0 \\
\hline Derby & 39.0 & 43.9 & & 55.6 & 73.0 & 90.9 & 85.2 & 92.9 & 82.4 & 78.6 \\
\hline Derry & & & & & & & 100.0 & 0.0 & 100.0 & * \\
\hline Donc & & & & & & & & 100.0 & 80.0 & 75.0 \\
\hline Dorset & & & & 31.7 & 72.2 & 77.8 & 75.0 & 68.4 & 71.4 & 80.0 \\
\hline Dudley & 29.0 & 4.5 & 33.3 & 0.0 & 0.0 & 0.0 & 0.0 & 0.0 & 0.0 & 0.0 \\
\hline Dundee & 75.0 & 72.2 & 60.4 & 59.5 & 61.9 & 30.6 & 19.0 & 23.1 & 40.0 & 90.0 \\
\hline Dunfn & 81.0 & 85.2 & 80.0 & 66.7 & 73.3 & 64.0 & 60.0 & 66.7 & 40.0 & 83.3 \\
\hline Edinb & 76.0 & 59.5 & 56.9 & 42.0 & 53.7 & 51.1 & 64.4 & 86.2 & 100.0 & 100.0 \\
\hline Exeter & 28.0 & 25.9 & 20.0 & 25.4 & 14.5 & 9.7 & 7.0 & 0.0 & 2.6 & 0.0 \\
\hline Glasgw & 53.0 & 58.9 & 55.7 & 57.2 & 48.2 & 57.9 & 67.4 & 85.0 & 88.6 & 82.6 \\
\hline Glouc & 53.0 & 71.9 & 53.1 & 51.4 & 60.6 & 56.7 & 20.8 & 54.5 & 57.1 & 81.8 \\
\hline Hull & 73.0 & 67.9 & 67.6 & 57.4 & 64.7 & 62.5 & 47.1 & 63.3 & 32.1 & 18.2 \\
\hline Inverns & 27.0 & 8.3 & 21.1 & 14.3 & 11.1 & 33.3 & 40.0 & 37.5 & 100.0 & 33.3 \\
\hline Ipswi & & & 19.4 & 25.0 & 32.0 & 17.2 & 46.7 & 7.7 & 0.0 & 0.0 \\
\hline Kent & & & & & & & & 56.8 & 51.7 & 43.8 \\
\hline Klmarnk & 7.7 & 14.3 & 28.6 & 33.3 & 30.0 & 30.4 & 37.5 & 85.7 & 85.7 & 66.7 \\
\hline
\end{tabular}


Table 6.18. Continued

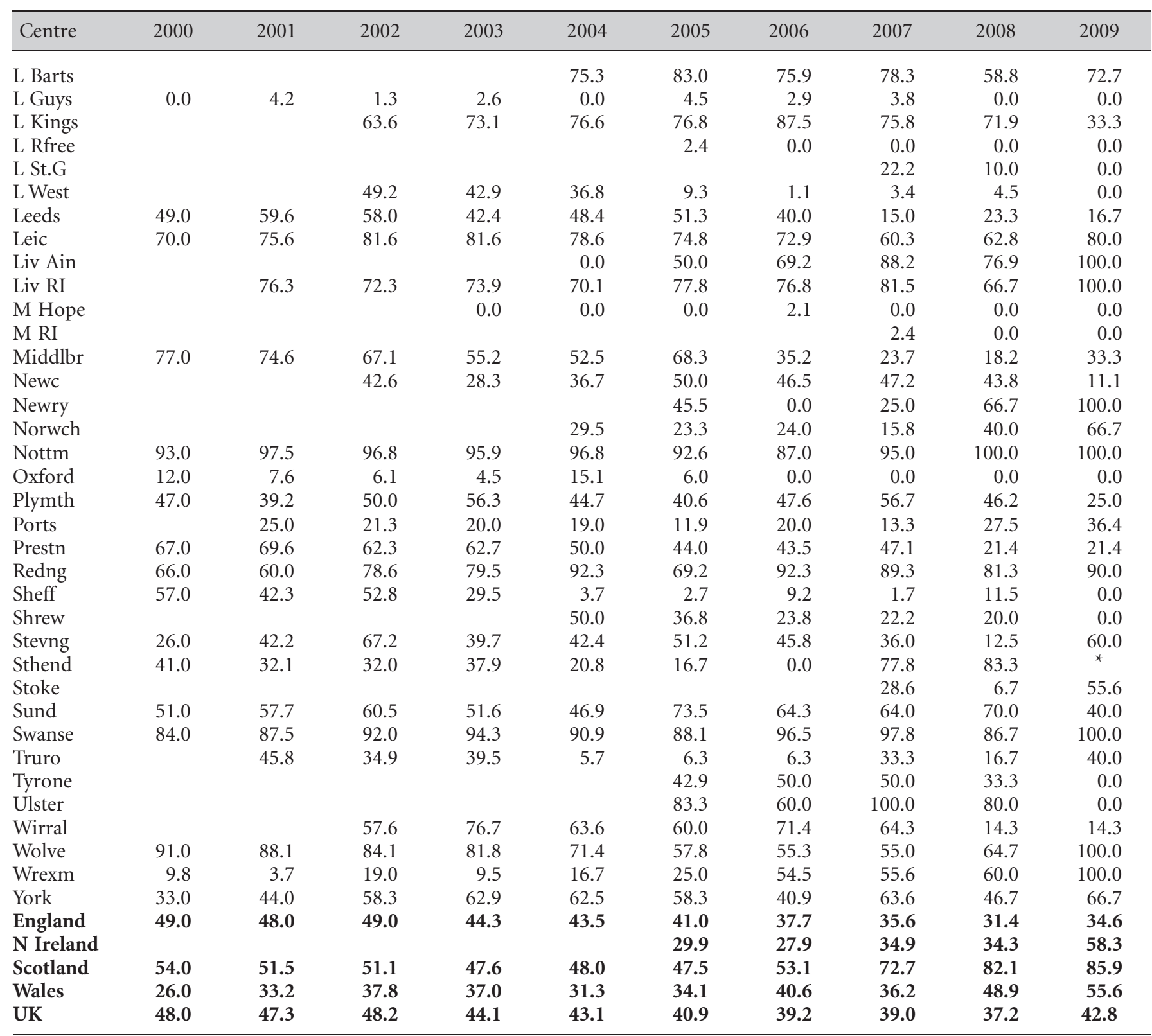

Blank cells, data not available for that year

${ }^{*}$ no deaths recorded

these data were entered. The Scottish centres overall had the highest rate of data return. Several centres have shown significant improvement in data returns but others that were reporting these data in previous years appear to have discontinued collection.

\section{Causes of death in incident RRT patients \\ Causes of death within the first 90 days \\ See table 6.19.}

Causes of death within one year after 90 days

Treatment withdrawal as a cause of death (table 6.19 and table 6.20) was more common in the older age group.

Causes of death in prevalent RRT patients in 2009

Table 6.21 and figures 6.25 and 6.26 show the frequency of the causes of death for both prevalent dialysis and transplant patients. These data are neither age-adjusted nor 
Table 6.19. Cause of death in the first 90 days for incident patients by age, 2000-2008

\begin{tabular}{|c|c|c|c|c|c|c|}
\hline \multirow[b]{2}{*}{ Cause of death } & \multicolumn{2}{|c|}{ All age groups } & \multicolumn{2}{|c|}{$<65$ years } & \multicolumn{2}{|c|}{$\geqslant 65$ years } \\
\hline & Number of deaths & $\%$ & Number of deaths & $\%$ & Number of deaths & $\%$ \\
\hline Cerebrovascular disease & 86 & 5 & 20 & 5 & 66 & 5 \\
\hline Infection & 292 & 17 & 47 & 13 & 245 & 19 \\
\hline Malignancy & 137 & 8 & 37 & 10 & 100 & 8 \\
\hline Uncertain & 282 & 17 & 73 & 20 & 209 & 16 \\
\hline Total & 1,689 & & 367 & & 1,322 & \\
\hline No cause of death data & 2,120 & & 470 & & 1,650 & \\
\hline
\end{tabular}

Table 6.20. Cause of death in 1 year after 90 days for incident patients by age, 2000-2008

\begin{tabular}{|c|c|c|c|c|c|c|}
\hline Cause of death & \multicolumn{2}{|c|}{ All age groups } & \multicolumn{2}{|c|}{$<65$ years } & \multicolumn{2}{|c|}{$\geqslant 65$ years } \\
\hline Cerebrovascular disease & 152 & 5 & 40 & 5 & 112 & 6 \\
\hline Infection & 512 & 18 & 149 & 19 & 363 & 18 \\
\hline Malignancy & 282 & 10 & 100 & 13 & 182 & 9 \\
\hline Uncertain & 529 & 19 & 159 & 20 & 370 & 18 \\
\hline Total & 2,805 & & 799 & & 2,006 & \\
\hline No cause of death data & 3,637 & & 1,047 & & 2,590 & \\
\hline
\end{tabular}

adjusted for differences in the comorbidity between the two groups. Cardiac disease as a cause of death was less common in the transplanted patients as these were a pre-selected low risk group of patients. Malignancy and infection were both responsible for a greater percentage of deaths in the transplanted group. Treatment withdrawal still occurs in the transplanted group, in patients who choose not to restart dialysis when their renal transplant fails.
Table 6.22 shows there were no differences in the causes of death between transplanted patients aged $<55$ or $\geqslant 55$ years. Table 6.23 shows these data for dialysis patients. Dialysis patients aged 65 years and over were significantly more likely to withdraw from treatment than younger patients but otherwise causes of death were similar in both age groups.

Table 6.21 Cause of death in prevalent RRT patients by age and modality on $1 / 1 / 2009$

\begin{tabular}{|c|c|c|c|c|c|c|}
\hline \multirow[b]{2}{*}{ Cause of death } & \multicolumn{2}{|c|}{ All age groups } & \multicolumn{2}{|l|}{ Dialysis } & \multicolumn{2}{|c|}{ Transplant } \\
\hline & Number of deaths & $\%$ & Number of deaths & $\%$ & Number of deaths & $\%$ \\
\hline Cardiac disease & 381 & 23 & 341 & 24 & 40 & 18 \\
\hline Cerebrovascular disease & 76 & 5 & 68 & 5 & 8 & 4 \\
\hline Infection & 339 & 21 & 279 & 19 & 60 & 28 \\
\hline Malignancy & 150 & 9 & 101 & 7 & 49 & 23 \\
\hline Treatment withdrawal & 208 & 13 & 207 & 14 & 1 & 0 \\
\hline Other & 150 & 9 & 127 & 9 & 23 & 11 \\
\hline Uncertain & 348 & 21 & 312 & 22 & 36 & 17 \\
\hline Total & 1,652 & & 1,435 & & 217 & \\
\hline No cause of death data & 2,352 & & 1,965 & & 387 & \\
\hline
\end{tabular}




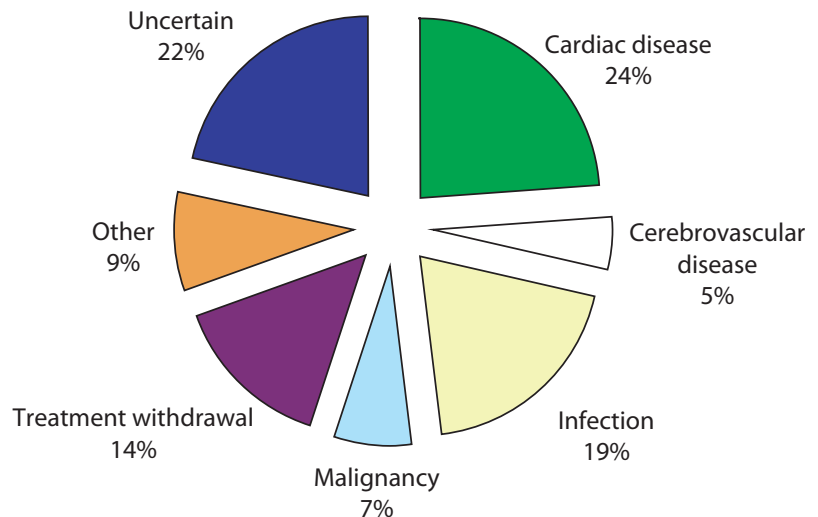

Fig. 6.25. Frequency of causes of death for prevalent dialysis patients in 2009

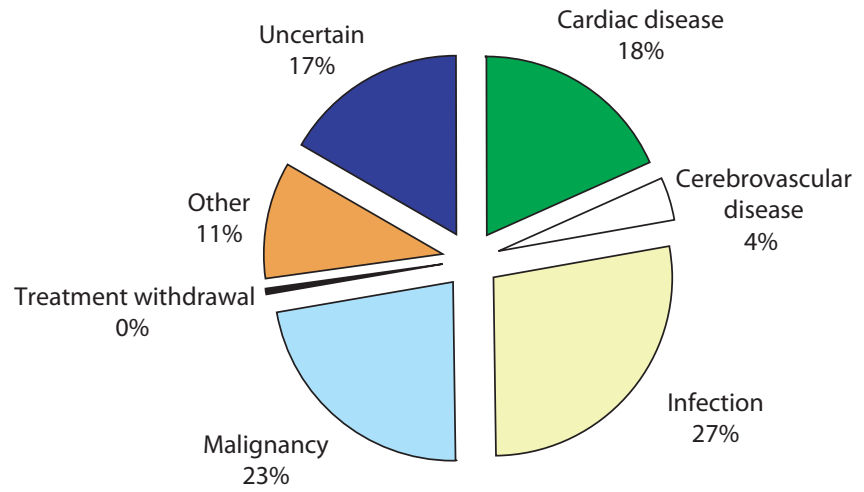

Fig. 6.26. Frequency of causes of death for prevalent transplant patients in 2009

Table 6.22. Cause of death in prevalent transplanted patients by age on $1 / 1 / 2009$

\begin{tabular}{|c|c|c|c|c|c|c|}
\hline \multirow[b]{2}{*}{ Cause of death } & \multicolumn{2}{|c|}{ All age groups } & \multicolumn{2}{|c|}{$<55$ years } & \multicolumn{2}{|c|}{$\geqslant 55$ years } \\
\hline & Number of deaths & $\%$ & Number of deaths & $\%$ & Number of deaths & $\%$ \\
\hline Cardiac disease & 40 & 18 & 10 & 16 & 30 & 19 \\
\hline Cerebrovascular disease & 8 & 4 & 3 & 5 & 5 & 3 \\
\hline Infection & 60 & 28 & 19 & 31 & 41 & 26 \\
\hline Malignancy & 49 & 23 & 10 & 16 & 39 & 25 \\
\hline Treatment withdrawal & 1 & 0 & 0 & 0 & 1 & 1 \\
\hline Other & 23 & 11 & 9 & 15 & 14 & 9 \\
\hline Uncertain & 36 & 17 & 10 & 16 & 26 & 17 \\
\hline Total & 217 & & 61 & & 156 & \\
\hline No cause of death data & 387 & & 106 & & 281 & \\
\hline
\end{tabular}

\section{Expected life years remaining on RRT}

For the statistical methodology for this analysis please refer to the methodology section at the start of this chapter.

Figure 6.27 shows the median remaining life years expected by age band. All incident patients starting RRT from 1997 to 2008 have been included in this analysis and the projected median survival will be different for low risk (e.g. polycystic kidney disease with a transplant) vs. high risk (diabetic with previous myocardial infarction on dialysis) patients even within the same age band.

Conflicts of interest: none

Table 6.23. Cause of death in prevalent dialysis patients by age on $1 / 1 / 2009$

\begin{tabular}{|c|c|c|c|c|c|c|}
\hline \multirow[b]{2}{*}{ Cause of death } & \multicolumn{2}{|c|}{ All age groups } & \multicolumn{2}{|c|}{$<65$ years } & \multicolumn{2}{|c|}{$\geqslant 65$ years } \\
\hline & Number of deaths & $\%$ & Number of deaths & $\%$ & Number of deaths & $\%$ \\
\hline Cardiac disease & 341 & 24 & 108 & 24 & 233 & 23 \\
\hline Cerebrovascular disease & 68 & 5 & 20 & 5 & 48 & 5 \\
\hline Infection & 279 & 19 & 94 & 21 & 185 & 19 \\
\hline Malignancy & 101 & 7 & 31 & 7 & 70 & 7 \\
\hline Treatment withdrawal & 207 & 14 & 43 & 10 & 164 & 17 \\
\hline Other & 127 & 9 & 57 & 13 & 70 & 7 \\
\hline Uncertain & 312 & 22 & 90 & 20 & 222 & 22 \\
\hline Total & 1,435 & & 443 & & 992 & \\
\hline No cause of death data & 1,965 & & 562 & & 1,403 & \\
\hline
\end{tabular}




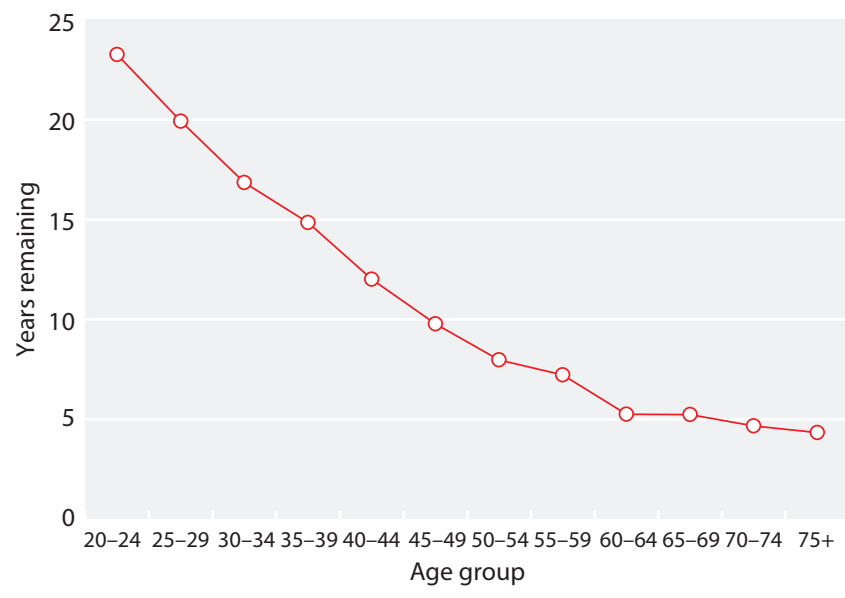

Fig. 6.27. Median remaining life years on RRT by age band, 2009

\section{References}

1 Miskulin DC, Meyer KB, Martin AA, Fink NE, Coresh J, Powe NR, et al. Comorbidity and its change predict survival in incident dialysis patients. American journal of kidney diseases: the official journal of the National Kidney Foundation 2003;41(1):149-161

2 Plantinga LC, Fink NE, Levin NW, Jaar BG, Coresh J, Levey AS, et al. Early, Intermediate, and Long-Term Risk Factors for Mortality in Incident Dialysis Patients: The Choices for Healthy Outcomes in Caring for ESRD (CHOICE) Study. American journal of kidney diseases: the official journal of the National Kidney Foundation 2007; 49(6):831-840

-3 Tomson C, Maggs C. UK Renal Registry 12th Annual Report (December 2009): chapter 2: introduction. Nephron Clin Pract 2010;115(Suppl 1):c3-8

4 Ford DJ, Fogarty DG, Steenkamp R, Tomson CRV, Ben-Shlomo Y, Ansell D. Chapter 13: The UK Renal Registry Advanced CKD Study: frequency of incorrect reporting of date of start of RRT. Nephron Clinical Practice; 115(Suppl. 1):c271-c278

5 Office National Statistics http://www.statistics.gov.uk/statbase/Product. asp?vlnk $=14409$
6 http://www.renal.org/clinical/GuidelinesSection/Guidelines.aspx

7 Ansell D, Roderick P, Hodsman A, Ford D, Steenkamp R, Tomson C. UK Renal Registry 11th Annual Report (December 2008): Chapter 7 Survival and causes of death of UK adult patients on renal replacement therapy in 2007: national and centre-specific analyses. Nephron Clin Pract 2009;111(Suppl 1):c113-139

8 Office for National Statistics. www.ons.gov.uk

9 Yoshino M, Kuhlmann MK, Kotanko P, Greenwood RN, Pisoni RL, Port FK, et al. International Differences in Dialysis Mortality Reflect Background General Population Atherosclerotic Cardiovascular Mortality. Journal of the American Society of Nephrology 2006 December 1, 2006;17(12):3510-3519

10 US Renal Data System, USRDS 2009 Annual Data Report: Atlas of Chronic Kidney Disease and End-Stage Renal Disease in the United States, National Institutes of Health, National Institute of Diabetes and Digestive and Kidney Diseases 2009 


\section{Appendix 1: Survival tables}

Table 6.24. One-year after 90-day incident survival by centre for 2008, unadjusted and adjusted to age 60

\begin{tabular}{|c|c|c|c|c|c|c|c|}
\hline Centre & $\begin{array}{c}\text { Unadjusted } \\
1 \text { yr after } 90 \mathrm{~d} \\
\text { survival }\end{array}$ & $\begin{array}{c}\text { Adjusted } \\
1 \text { yr after } 90 \mathrm{~d} \\
\text { survival }\end{array}$ & $\begin{array}{c}\text { Adjusted } \\
1 \text { yr after } 90 \mathrm{~d} \\
95 \% \mathrm{CI}\end{array}$ & Centre & $\begin{array}{l}\text { Unadjusted } \\
1 \text { yr after } 90 \mathrm{~d} \\
\text { survival }\end{array}$ & $\begin{array}{c}\text { Adjusted } \\
1 \text { yr after } 90 \mathrm{~d} \\
\text { survival }\end{array}$ & $\begin{array}{c}\text { Adjusted } \\
1 \text { yr after } 90 \mathrm{~d} \\
95 \% \mathrm{CI}\end{array}$ \\
\hline Abrdn & 92.52 & 94.05 & $88.6-99.8$ & L Rfree & 94.49 & 95.30 & $92.4-98.3$ \\
\hline Airdrie & 89.19 & 90.96 & $83.1-99.6$ & L St.G & 90.84 & 92.33 & $87.4-97.6$ \\
\hline Antrim & 94.44 & 96.55 & $92.1-100.0$ & L West & 93.08 & 94.21 & $91.8-96.7$ \\
\hline B Heart & 91.27 & 93.05 & $88.5-97.8$ & Leeds & 89.59 & 91.24 & $87.1-95.6$ \\
\hline B QEH & 86.46 & 89.04 & $85.5-92.7$ & Leic & 89.43 & 91.59 & $88.3-95.0$ \\
\hline Bangor & 84.94 & 90.23 & $81.6-99.8$ & Liv Ain & 80.56 & 84.56 & $74.8-95.6$ \\
\hline Basldn & 89.74 & 92.46 & $85.7-99.7$ & Liv RI & 94.77 & 95.53 & $91.8-99.4$ \\
\hline Belfast & 82.95 & 87.75 & $81.2-94.8$ & M Hope & 85.79 & 87.07 & $81.6-92.9$ \\
\hline Bradfd & 85.42 & 84.86 & $75.8-95.0$ & M RI & 91.22 & 91.71 & $87.1-96.5$ \\
\hline Brightn & 80.73 & 86.71 & $81.6-92.1$ & Middlbr & 82.59 & 85.81 & $79.4-92.7$ \\
\hline Bristol & 81.19 & 84.39 & $79.4-89.7$ & Newc & 90.66 & 92.04 & $86.9-97.5$ \\
\hline Camb & 89.62 & 92.81 & $88.8-97.0$ & Newry & 85.71 & 88.40 & $77.5-100.0$ \\
\hline Cardff & 85.31 & 87.78 & $83.0-92.8$ & Norwch & 86.83 & 90.86 & 85.9-96.2 \\
\hline Carlis & 83.33 & 85.49 & $74.8-97.7$ & Nottm & 88.41 & 90.29 & $85.2-95.7$ \\
\hline Carsh & 81.90 & 86.81 & $82.8-91.1$ & Oxford & 88.42 & 90.77 & $86.4-95.4$ \\
\hline Chelms & 90.91 & 94.34 & $88.4-100.0$ & Plymth & 88.79 & 91.27 & $85.3-97.6$ \\
\hline Colchr & 77.95 & 85.30 & 77.9-93.4 & Ports & 85.00 & 87.79 & $83.1-92.7$ \\
\hline Covnt & 84.07 & 86.96 & $81.2-93.2$ & Prestn & 78.03 & 80.34 & $73.4-87.9$ \\
\hline Derby & 89.77 & 92.45 & $87.8-97.3$ & Redng & 94.23 & 95.15 & $91.1-99.4$ \\
\hline Donc & 90.15 & 92.18 & $82.7-100.0$ & Sheff & 94.22 & 96.00 & $93.6-98.5$ \\
\hline Dorset & 88.83 & 92.65 & $87.9-97.7$ & Shrew & 88.33 & 92.48 & $87.3-98.0$ \\
\hline Dudley & 66.02 & 66.12 & $53.3-82.1$ & Stevng & 90.51 & 91.82 & $86.8-97.1$ \\
\hline Dundee & 82.67 & 88.99 & $82.5-96.0$ & Sthend & 79.31 & 84.07 & $73.4-96.3$ \\
\hline Dunfn & 90.00 & 92.99 & $85.8-100.0$ & Stoke & 89.40 & 91.60 & $86.2-97.3$ \\
\hline Edinb & 79.71 & 83.36 & $76.6-90.7$ & Sund & 84.09 & 86.23 & $77.4-96.1$ \\
\hline Exeter & 80.99 & 87.51 & $82.8-92.5$ & Swanse & 80.74 & 84.87 & $79.2-90.9$ \\
\hline Glasgw & 85.25 & 88.03 & $83.3-93.0$ & Truro & 88.19 & 91.86 & $84.6-99.7$ \\
\hline Glouc & 95.35 & 96.47 & $91.9-100.0$ & Tyrone & 95.83 & 97.21 & $92.1-100.0$ \\
\hline Hull & 84.48 & 87.26 & $81.6-93.3$ & Wirral & 89.19 & 91.09 & $83.2-99.7$ \\
\hline Inverns & 87.62 & 90.71 & $81.4-100.0$ & Wolve & 86.62 & 88.82 & $82.8-95.2$ \\
\hline Ipswi & 97.37 & 97.54 & $93.0-100.0$ & York & 72.87 & 81.58 & 70.7-94.1 \\
\hline Kent & 84.24 & 87.90 & $83.0-93.1$ & England & 87.73 & 90.15 & $89.3-91.0$ \\
\hline Klmarnk & 86.90 & 91.35 & $83.7-99.7$ & N Ireland & 87.09 & 90.91 & $87.2-94.7$ \\
\hline L Barts & 94.19 & 93.92 & $90.5-97.5$ & Scotland & 85.22 & 88.79 & $86.3-91.4$ \\
\hline L Guys & 88.87 & 90.27 & $86.0-94.8$ & Wales & 83.13 & 86.70 & $83.4-90.2$ \\
\hline L Kings & 86.55 & 88.89 & $84.3-93.8$ & UK & 87.28 & 89.89 & $89.0-90.7$ \\
\hline
\end{tabular}

Excluded: Data from centres with less than 20 patients are excluded (Clwyd, Derry, D \& Gall, Ulster, Wrexham) 
Table 6.25. Ninety day incident survival by centre for 2008, unadjusted and adjusted to age 60

\begin{tabular}{|c|c|c|c|c|c|c|c|}
\hline Centre & $\begin{array}{l}\text { Unadjusted } \\
90 \text { day survival }\end{array}$ & $\begin{array}{c}\text { Adjusted } \\
90 \text { day survival }\end{array}$ & $\begin{array}{c}\text { Adjusted } \\
90 \text { day } 95 \% \text { CI }\end{array}$ & Centre & $\begin{array}{c}\text { Unadjusted } \\
90 \text { day survival }\end{array}$ & $\begin{array}{c}\text { Adjusted } \\
90 \text { day survival }\end{array}$ & $\begin{array}{c}\text { Adjusted } \\
90 \text { day } 95 \% \text { CI }\end{array}$ \\
\hline Abrdn & 96.4 & 97.5 & $94.2-100.0$ & L West & 94.3 & 95.9 & $94.0-97.8$ \\
\hline Antrim & 90.0 & 94.8 & $90.0-99.9$ & Leic & 93.4 & 95.5 & $93.3-97.7$ \\
\hline B Heart & 91.4 & 94.5 & $91.0-98.1$ & Liv Ain & 85.7 & 90.7 & $83.9-98.0$ \\
\hline $\mathrm{B} \mathrm{QEH}$ & 91.4 & 94.1 & $91.8-96.5$ & Liv RI & 95.1 & 96.3 & $93.2-99.5$ \\
\hline Belfast & 97.1 & 98.2 & 95.9-100.0 & Middlbr & 93.5 & 95.7 & $92.4-99.1$ \\
\hline Bradfd & 92.1 & 93.0 & $87.3-99.1$ & Newc & 95.9 & 96.9 & $94.0-99.9$ \\
\hline Brightn & 95.9 & 97.8 & $95.9-99.7$ & Norwch & 95.5 & 97.5 & $95.1-99.9$ \\
\hline Bristol & 93.7 & 95.6 & $93.1-98.2$ & Nottm & 91.4 & 93.7 & $89.9-97.6$ \\
\hline Camb & 93.8 & 96.4 & $93.8-99.1$ & Oxford & 92.5 & 94.9 & $92.1-97.9$ \\
\hline Covnt & 93.9 & 95.5 & $92.3-98.8$ & Sheff & 96.7 & 98.0 & $96.5-99.6$ \\
\hline Derby & 95.7 & 97.2 & $94.6-99.9$ & Shrew & 98.4 & 99.1 & $97.5-100.0$ \\
\hline Donc & 88.5 & 92.7 & $85.3-100.0$ & Stevng & 95.1 & 96.3 & $93.1-99.5$ \\
\hline Dorset & 87.1 & 93.1 & $89.2-97.2$ & Sthend & 83.2 & 89.9 & $82.5-97.9$ \\
\hline Dudley & 89.4 & 92.3 & $86.1-98.9$ & Stoke & 92.7 & 95.1 & $91.3-99.0$ \\
\hline Dundee & 84.4 & 91.6 & $86.7-96.8$ & Sund & 97.8 & 98.3 & $95.1-100.0$ \\
\hline Edinb & 87.4 & 91.2 & $86.7-95.9$ & Swanse & 95.1 & 96.7 & $94.2-99.3$ \\
\hline Exeter & 91.8 & 95.7 & $93.3-98.3$ & Truro & 90.0 & 94.3 & $89.1-99.8$ \\
\hline Glasgw & 92.4 & 94.7 & 91.9-97.7 & Wirral & 92.9 & 95.2 & $90.2-100.0$ \\
\hline Glouc & 91.5 & 94.4 & $89.2-99.8$ & Wolve & 95.5 & 96.8 & $93.8-99.9$ \\
\hline Hull & 92.9 & 95.1 & $91.8-98.5$ & Wrexm & 85.7 & 89.7 & $80.1-100.0$ \\
\hline
\end{tabular}

Excluded: centres with data from less than 20 incident patients (Clwyd, Derry, D \& Gall, Ulster), centres with no deaths in 90 days (Carlisle, Dunfermline, Inverness, Ipswich, Newry, Tyrone) 
Table 6.26. One year after 90-day incident survival by centre for incident cohort years 2000-2008, adjusted to age 60

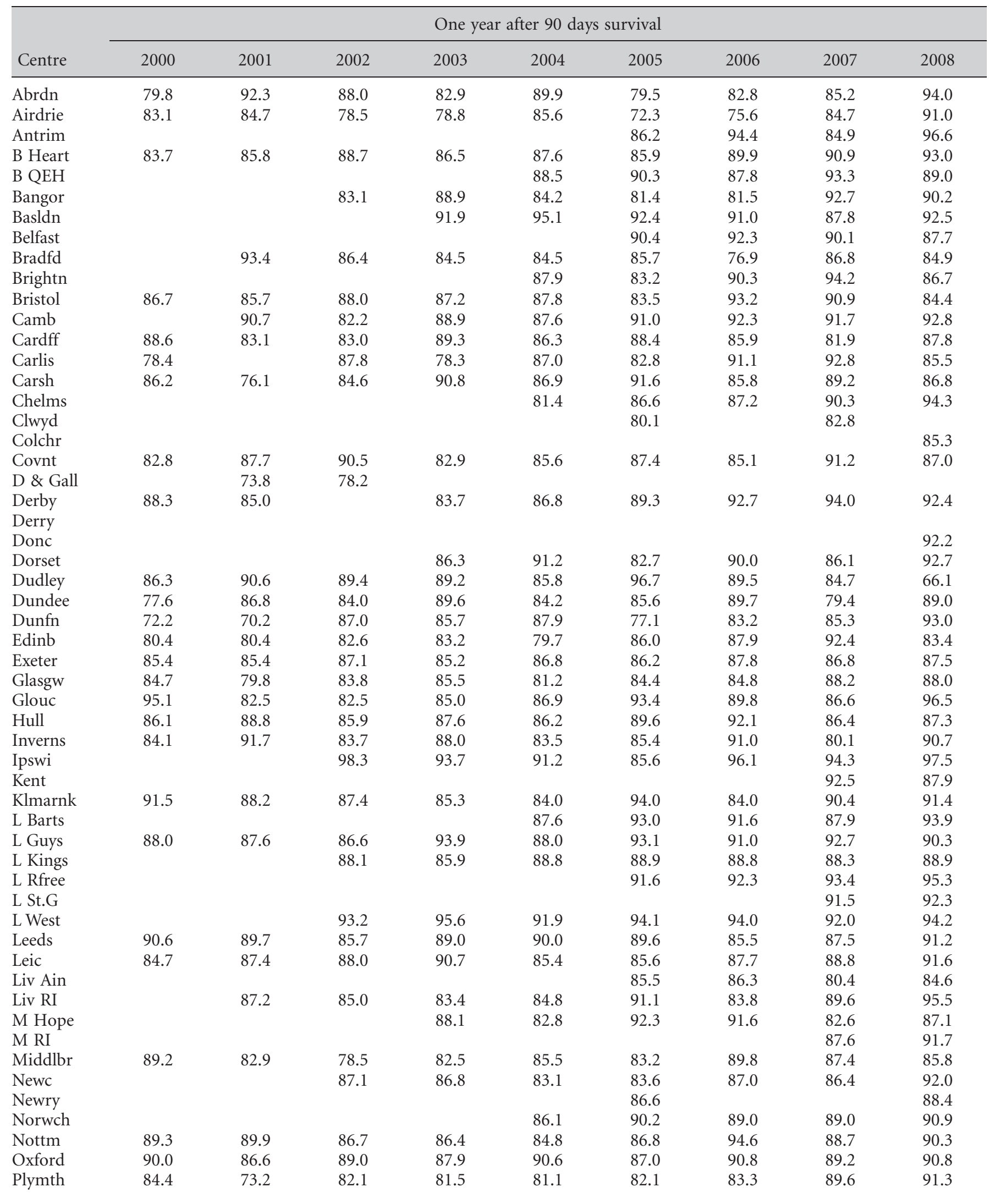


Table 6.26. Continued

\begin{tabular}{|c|c|c|c|c|c|c|c|c|c|}
\hline \multirow[b]{2}{*}{ Centre } & \multicolumn{9}{|c|}{ One year after 90 days survival } \\
\hline & 2000 & 2001 & 2002 & 2003 & 2004 & 2005 & 2006 & 2007 & 2008 \\
\hline Prestn & 87.0 & 87.2 & 86.7 & 86.0 & 84.5 & 92.0 & 84.8 & 89.2 & 80.3 \\
\hline Redng & 76.3 & 83.7 & 92.5 & 92.0 & 93.8 & 88.6 & 90.4 & 90.3 & 95.1 \\
\hline Sheff & 94.9 & 94.3 & 84.4 & 90.1 & 89.9 & 92.1 & 89.5 & 87.2 & 96.0 \\
\hline Sthend & 82.5 & 80.5 & 87.7 & 90.8 & 87.3 & 92.3 & 96.4 & 92.1 & 84.1 \\
\hline Stoke & & & & & & & & 85.5 & 91.6 \\
\hline Sund & 83.6 & 85.2 & 71.3 & 81.4 & 88.1 & 82.5 & 82.6 & 87.6 & 86.2 \\
\hline Swanse & 84.9 & 85.6 & 83.4 & 82.4 & 82.3 & 84.2 & 83.5 & 89.5 & 84.9 \\
\hline Truro & & 91.4 & 84.0 & 88.6 & 92.4 & 88.1 & 92.8 & 86.6 & 91.9 \\
\hline Tyrone & & & & & & & 89.8 & 89.7 & 97.2 \\
\hline York & 83.6 & 87.0 & 82.4 & 78.7 & 90.0 & 85.3 & 83.2 & 94.6 & 81.6 \\
\hline England & 87.5 & 86.5 & 86.6 & 88.2 & 87.7 & 88.6 & 89.4 & 89.6 & 90.2 \\
\hline N Ireland & & & & & & 89.8 & 91.8 & 89.6 & 90.9 \\
\hline Scotland & 82.1 & 82.7 & 83.8 & 85.4 & 83.7 & 84.0 & 85.0 & 86.6 & 88.8 \\
\hline Wales & 87.0 & 84.1 & 84.5 & 85.9 & 85.7 & 86.3 & 85.6 & 85.7 & 86.7 \\
\hline UK & 86.4 & 85.8 & 86.1 & 87.7 & 87.2 & 88.0 & 88.9 & 89.1 & 89.9 \\
\hline
\end{tabular}

Blank cells: centres with $<20$ patients for that year or centres with no data available for that year 
Table 6.27. One year prevalent survival by centre for prevalent cohort years $2000-2009$, adjusted to age 60

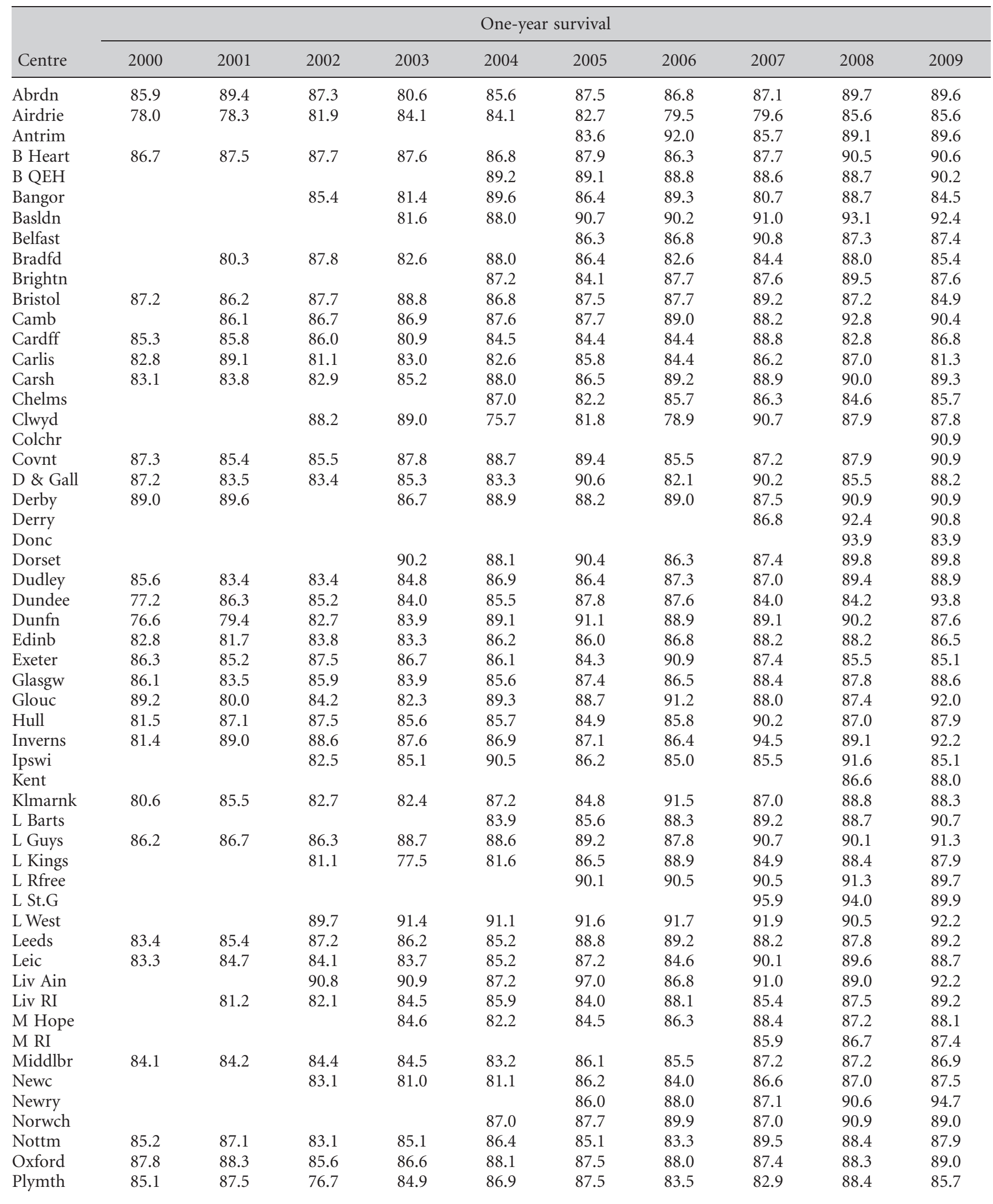


Table 6.27. Continued

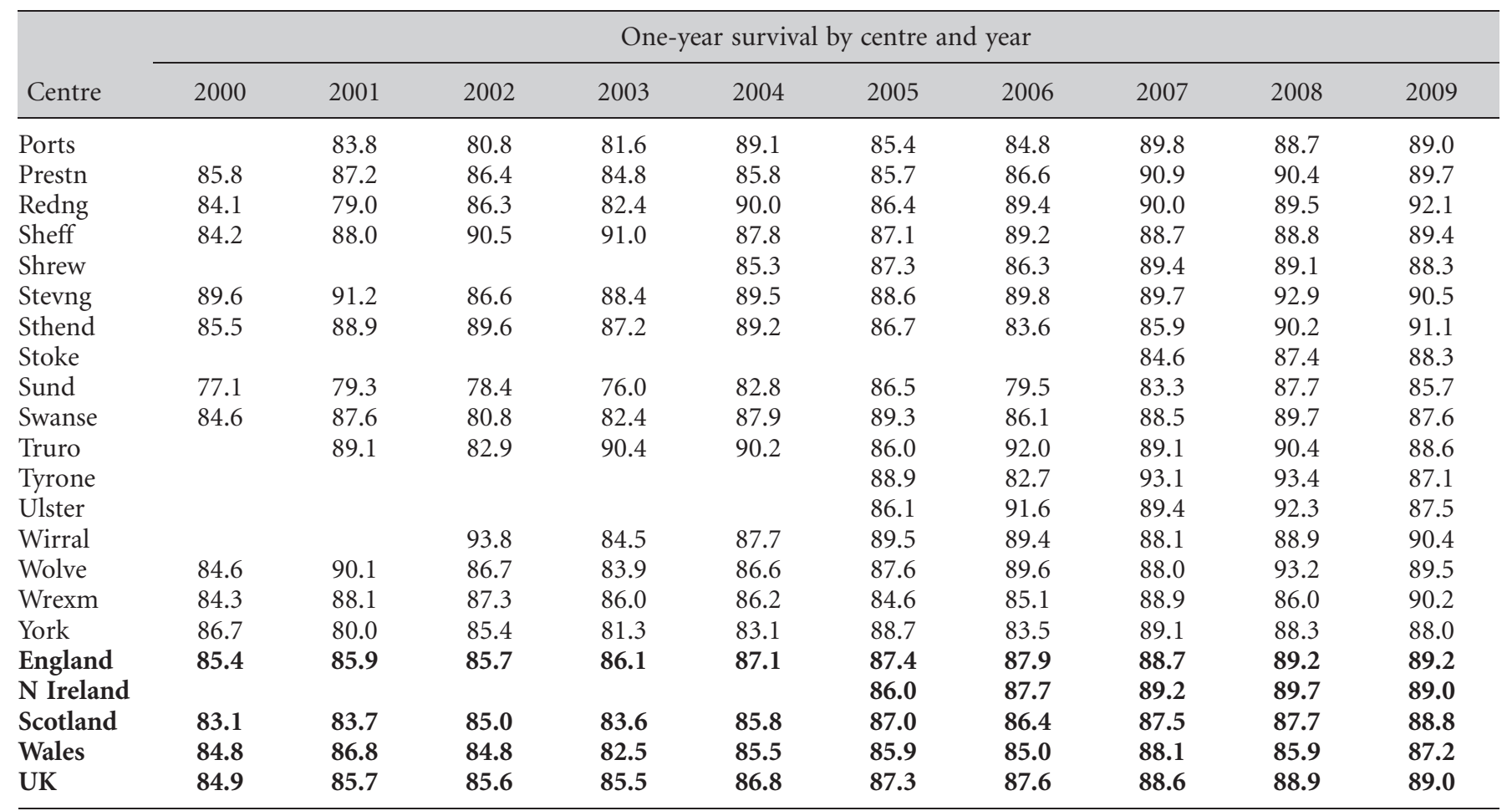

Blank cells: data not available for that year or less than 20 patients in that year 